\title{
Gridlock, leverage, and policy bundling
}

\author{
Barton E. Lee* \\ Latest version here \\ June 23,2020
}

\begin{abstract}
We consider a dynamic model of bargaining where alternatives to the status-quo arrive stochastically during the bargaining process, the proposer can bundle multiple alternatives into a single proposal, and a forward-looking voter elects the agendasetter. We show that the prevailing wisdom that policy bundling reduces gridlock — by facilitating compromise across different policy areas - is incomplete. Policy bundling can also increase gridlock: a player may veto or delay a bipartisan alternative, which is unanimously preferred to the status-quo, so that in the future they can bundle this same alternative with a divisive alternative that otherwise would not pass. Gridlock of this form is more likely to occur during periods of economic stability and suggests that traditional measures of legislator ideology will overstate polarization. From the voter's perspective, we show that gridlock occurs at an inefficiently high frequency. This state of "excess gridlock" is driven by the voter being forward-looking and lacking commitment power to punish players that veto.
\end{abstract}

Keywords: Gridlock, bargaining, policy bundling. JEL Classification: D72, D78.

*School of Economics, UNSW Sydney. Email: barton.e.lee@gmail.com. I owe thanks to Gabriele Gratton, Richard Holden, and Hongyi Li for helpful discussions and feedback, and also to seminar participants at the UNSW Theory Workshop. 


\section{Introduction}

Congress' inability to pass legislation is a defining characteristic of the modern era. Since the 1950s, legislative gridlock has doubled in frequency (Binder, 2014) and, in October 2013 alone, was estimated to have cost the U.S. economy \$24 billon (Lowrey, Popper and Schwartz, 2013). Nonetheless, many argue that gridlock would be more frequent if legislators were unable to engage in policy bundling, whereby legislators bundle diverse and unrelated proposals into a single piece of legislation. ${ }^{1}$ By bundling policies, legislators can build compromises and pass policies that otherwise would not pass (Krutz, 2000. 2001: Sinclair, 1997). ${ }^{2}$ As stated by former U.S. Senator Lieberman, "leadership often resorts to a tactic of passing unpopular ideas by attaching them to bills supported on both sides of the aisle" (Lieberman, 2020).

Yet, the argument that policy bundling reduces gridlock presents a puzzle. Unlike in the U.S. Congress, policy bundling is unconstitutional or ineffective in almost all U.S. state legislatures because of single-subject and line-item veto rules (Brown, 2012). ${ }^{3}$ However, even in highly-polarized states, gridlock is less frequent than in the U.S. Congress (Masket, 2019).

We argue that the prevailing wisdom surrounding policy bundling is incomplete. In a dynamic environment, where alternatives to the status-quo arrive over time, policy bundling also creates an incentive for parties to induce gridlock. By blocking a proposal today, a party may benefit tomorrow since they can bundle this same proposal with a divisive alternative that otherwise would not pass. In the words of Senator Lieberman, "Some of the most popular ideas are in many cases held in abeyance so that they can be used to

\footnotetext{
${ }^{1}$ Policy bundling is similar but differs from vote trading or logrolling (Buchanan and Tullock. 1962) since the latter can generate commitment problems (Weingast and Marshall, 1988).

${ }^{2}$ Policy bundling is frequently used by Congress. Casas, Denny and Wilkerson (2020) analyze the presence of hitchhiker bills: bills that were initially proposed and failed to enacted, but then later became law as a provision of another bill. They show that, between 1993 and 2014, more bills were enacted as hitchhiker bills than were enacted on their own.

${ }^{3}$ There are four states without either rule: New Hampshire, North Carolina, Rhode Island, and Vermont. For a brief period starting in 1996, President Clinton had a line-item veto until it was ruled to be unconstitutional by the Supreme Court in 1998. The U.S. Congress has never adopted a single-subject rule.
} 
pass legislation that most members would oppose if considered separately."

In this paper, we study a dynamic model of bargaining with policy bundling. Our main insight is that policy bundling - in addition to facilitating compromise, which reduces gridlock - can generate a perverse incentive that increases gridlock. We then derive conditions that cause gridlock to be more likely to occur, study the implications for voter welfare, and explore the empirical implications of our results. Finally, we discuss our model's insights for the long-running debate of whether policy bundling should be removed from Congress via constitutional reform. ${ }^{4}$

We consider a two-period bargaining game with two parties and a voter. At the start of period 1 , an alternative to the status-quo is realized which may or may not be available in period 2. The proposer then decides whether to propose this alternative as a take-itor-leave-it offer to the receiver. At the end of period 1, the voter decides which party will be the proposer for period 2. As in period 1, in period 2, a new alternative to the status-quo is realized, and the period-2 proposer decides whether to make a take-it-orleave-it proposal. However, the set of proposals that can be made now depends on the period-1 bargaining outcome. If the period-1 alternative passed in period 1, then it will not be available as a proposal in period 2, and the proposer simply decides whether to propose the period-2 alternative. If the period-1 alternative did not pass in period 1, then with some probability it will be available as a proposal. ${ }^{5}$ In this case, the proposer decides whether to propose each alternative separately or to "bundle" the alternatives into a single proposal. By bundling the alternatives, the proposer forces the receiver to either accept both alternatives or reject both.

Each period's alternative has a known voter-welfare component and an ex-ante un-

\footnotetext{
${ }^{4}$ This debate dates back as far as 98 B.C. when the Roman Republic made policy bundling unlawful via the Lex Caecilia Didia (Gilbert. 2006). More recently, President Trump has called on Congress to provide him with a line-item veto, which would render policy bundling ineffective (Nelson. 2018).

${ }^{5}$ The probability that an unpassed alternative will be available as a future proposal may be specific to the alternative itself or may depend on features of the policy-making environment. For example, during periods of economic stability, an unpassed alternative may be more likely to be available in the future.
} 
known partisan component. ${ }^{6}$ The voter's payoff is equal to the voter-welfare component, and each party's payoff depends on both the voter-welfare and partisan components. The partisan component increases the payoff of one party but decreases that of the other party. Alternatives that have a small partisan component provide both parties with positive payoffs and, hence, are said to be bipartisan; otherwise, they are said to be divisive.

Our model shows that policy bundling can increase gridlock. As per the prevailing wisdom, policy bundling will sometimes reduce gridlock by facilitating compromise: parties will agree to pass a bundle of alternatives if the benefits of passing each alternative that they prefer outweighs the cost of passing each alternative that they don't (Krutz, 2000, 2001; Sinclair, 1997). However, we show that policy bundling also creates an incentive for parties to gridlock bipartisan alternatives. Preventing a bipartisan alternative from passing is costly, but it also provides benefits. By vetoing such an alternative, a party (if elected) may benefit in the future since they will be able to bundle this same alternative with future alternatives that are divisive and otherwise would not pass. That is, the vetoed alternative can be used as leverage in future negotiations. This leverage incentive only exists because of policy bundling and can induce gridlock; we call gridlock of this form leverage-based gridlock. Leverage-based gridlock differs from gridlock which arises when an alternative is divisive; we call gridlock of this form preference-based gridlock. ${ }^{7}$

Leverage-based gridlock will occur more frequently when alternatives are more partisan or unpassed alternatives are more likely to be available in the future. When a party engages in leverage-based gridlock there are two costs. First, the unpassed alternative may be unavailable in the future, in which case the party forgoes any payoff associated with the alternative and there is no leverage benefit. Second, there is a cost of delay because future payoffs are discounted. As a bipartisan alternative becomes more partisan, ${ }^{8}$ one party's payoff from passing the alternative decreases, and this leads them to face a

\footnotetext{
${ }^{6}$ These components are realized at the start of the respective period.

7Preference-based gridlock aligns with the notion of a "gridlock interval" (Romer and Rosenthal, 1978).

${ }^{8}$ I.e., the alternative has a larger partisan component.
} 
smaller cost of delay. Hence, they are more likely to engage in leverage-gridlock. Similarly, leverage-based gridlock will be more frequent when unpassed alternatives are more likely to be available in the future, e.g., during times of economic stability.

Contrary to standard models of bargaining, we show that an increase in polarization can have a non-monotonic effect on the frequency of gridlock. We measure polarization by the likelihood that each period's alternative has a large partisan component. Polarization affects not only the likelihood that an alternative is divisive or bipartisan but also the leverage incentive of parties. When polarization is low or high, there is no leverage incentive and bipartisan alternatives are never gridlocked. This is because future alternatives will be bipartisan (when polarization is low) or likely to be so divisive that even with leverage it will be impossible to facilitate compromise (when polarization is high). However, when polarization is intermediate, gridlock may reach its highest levels. This is because there is now a leverage incentive: future alternatives are likely to be only "slightly" divisive and, hence, the leverage provided by an unpassed alternative will be sufficient to facilitate compromise.

Leverage-based gridlock is driven by the voter being forward-looking. In our model, the voter rationally elects the party that is likely to pass the most alternatives. This behavior is intuitive - voters want to elect politicians that "get stuff done" (Rivlin, 2018). However, this also implies that, conditional on an alternative failing to pass, one party will be electorally-advantaged and elected with certainty. The forward-looking behavior of the voter leads this electorally-advantaged party to have a greater incentive to engage in leverage-based gridlock. ${ }^{9}$ Without the electoral advantage, vetoing an alternative comes with an additional risk: the other party may be elected and the unpassed alternative may be used as leverage against the vetoing party. Thus, the voter's desire to elect a politician that will be productive in the future can, perhaps counter-intuitively, encourage politicians to gridlock present-day policies.

\footnotetext{
${ }^{9}$ As discussed in Appendix A this incentive is even stronger if parties receive electoral benefits (unrelated to policy outcomes) from being elected.
} 
In equilibrium, gridlock occurs in excess. From the voter's perspective, gridlock is costly but also entails benefits since, if the unpassed alternative is available, more alternatives are likely to be passed in the future. When the benefits outweigh the costs, we say that gridlock is efficient. This occurs when polarization is intermediate or unpassed alternatives are likely to be available in the future. In equilibrium, gridlock always occurs if it is efficient but may also occur when it is inefficient. This state of excess gridlock is driven by the voter's inability to commit. With commitment power, it is optimal for the voter to follow a "blame-game" strategy (à la Groseclose and McCarty (2001); Smith (1988)) whereby they never elect a vetoing party. Adopting this strategy enables the voter to completely eradicate inefficient leverage-based gridlock. Despite the appeal of this strategy, the empirical literature is divided on whether voters exhibit such retrospective behavior. $^{10}$

Our results have a number of empirical implications. First, the phenomenon of leverage-based gridlock suggests that traditional measures of ideology based on roll-call voting records (e.g., Poole and Rosenthal's (1985) NOMINATE methods) will overstate ideological disagreement between parties. Second, we predict that gridlock will be more frequent during periods of economic stability. These two predictions combine to provide a novel explanation for why measures of polarization have increased rapidly since the 1980s (Barber and McCarty, 2015). The 1980s marked the beginning of the Great Moderation, a period of economic stability, leading to more frequent leverage-based gridlock and, hence, overstated measures of polarization. This may also explain why within-Congress polarization compared to that within the public is more pronounced (Hetherington, 2001). Finally, our results suggest that direct measures of gridlock can also fail to capture ideological disagreement since gridlock and polarization have a non-monotonic relationship.

Related literature. This paper contributes to the literature on bargaining and gridlock. Within this literature, many causes of gridlock have been proposed; these include

\footnotetext{
${ }^{10}$ For example, Norpoth (1996) finds evidence that voters are retrospective, while Elinder, Jordahl and Poutvaara (2015) and MacKuen, Erikson and Stimson (1992) find evidence that voters are prospective.
} 
polarization (Romer and Rosenthal, 1978; Krehbiel, 1996), divided government (Binder, 2003), reputation concerns (McCarty, 1997; Abreu and Gul, 2000; Groseclose and McCarty, 2001: Cameron and McCarty, 2004; Patty, 2016), policy-search frictions (Callander, 2011; Acharya and Ortner, 2018), dynamic-bargaining concerns with an endogenous status-quo (Dziuda and Loeper, 2016; Austin-Smith, Dziuda, Harstad and Loeper, 2019), and supermajority institutions (Brady and Volden, 1998). Our paper highlights a new cause of gridlock that stems from policy bundling in dynamic environments; this effect runs contrary to the prevailing wisdom that policy bundling reduces gridlock by facilitating compromise (Krutz, 2000, 2001; Sinclair, 1997).

The leverage incentive that arises in our model connects with Callander and Martin's (2017: 2020) work on policy decay. In these papers, the quality of policies decay over time, and proposals that offer quality improvements can be combined with changes in the partisan component of the existing policy. This creates a leverage incentive - similar to that explored in the present paper. Our work differs from these papers in terms of our focus, which is on the relationship between policy bundling and gridlock. ${ }^{11}$ Our model also includes a strategic voter that elects the agenda-setter. This allows our model to speak to issues of voter welfare and is crucial to the incentives that we explore. ${ }^{12}$

The literature on policy bundling in bargaining games has focused on questions of when and why policy bundling benefits a proposer. In a complete information environment, Jackson and Moselle (2002) shows that policy bundling always benefits the proposer, and Chen and Eraslan (2014) extends this conclusion to an incomplete information setting with pre-play communication. However, in general, policy bundling need not benefit the proposer (Chakraborty and Harbaugh, 2003; Chen and Eraslan, 2013). Our

\footnotetext{
${ }^{11}$ There are also important differences between our models. In our model, the alternatives available to the proposer is constrained: alternatives arrive exogenously at the start of each period à la Acharya and Ortner (2018). In Callander and Martin (2017, 2020), the proposer is unconstrained: a proposal that improves a policy's quality can be combined with an arbitrary change in the policy's partisan component. This trivializes the policy bundling problem since the optimal "bundle" of quality improvement and partisan change is always available to the proposer.

${ }^{12}$ In fact, the leverage incentive of parties is strongest when the voter is strategic and forward-looking; when the voter has commitment power, the leverage incentive is non-existent.
} 


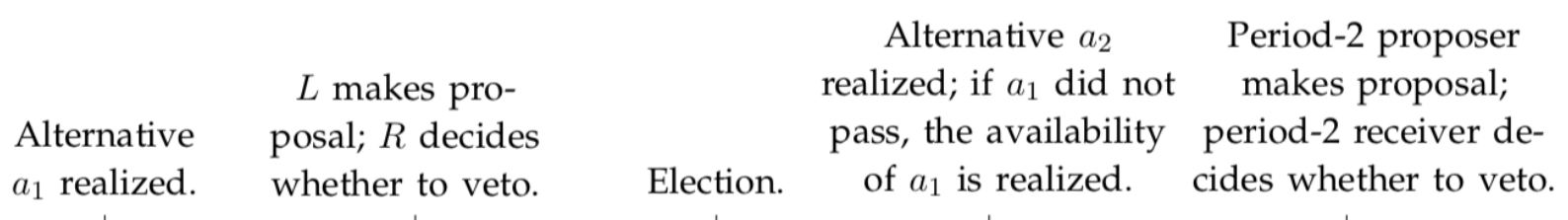

Figure 1: Timing of model.

work differs from these papers since we focus on the effect of allowing the proposer to (possibly) engage policy bundling on the frequency of gridlock.

Outline. The remainder of the paper is organized as follows. Section 2 introduces our model. Section 3 characterizes the equilibrium of our model. Section 4 analyzes comparative statics of gridlock. Section 5 explores the implications of our model for voter welfare. Section 6 considers our model's insights for the policy bundling debate. Section 7 discusses the empirical implications of our results and concludes the paper. All proofs appear in Appendix B.

\section{Model}

We now present the model. Figure 1 provides a summary of the model's timing, and Appendix Adiscusses some extensions of the model.

There are two parties, $L$ and $R$, that bargain for two periods $t=1,2$, and a voter, $V$. In each period, one party is the proposer and the other party is the receiver; without loss of generality, party $L$ is the period-1 proposer.

Period 1. At the start of period 1, an alternative to the status-quo, $a_{1}$, is realized which may or may not be available in period 2 . The proposer, $L$, then decides whether to propose $a_{1}$ to the receiver, $R$, who can veto the proposal. If $L$ does not propose $a_{1}$ or $R$ vetoes the proposal, then the status-quo prevails. Otherwise, the proposal is accepted and replaces the status-quo. Alternatives that are accepted are said to have passed. At the end of period 1 , there is an election, and the voter elects a party to be the proposer for period 2. 
Period 2. At the start of period 2, a new alternative to the status-quo, $a_{2}$, is realized and, if $a_{1}$ did not pass, the "availability" of $a_{1}$ is realized. The availability of $a_{1}$ is an exante unknown variable that indicates whether $a_{1}$ will be available as a proposal in period 2. If $a_{1}$ passed in period 1 , then it is never available. If $a_{1}$ did not pass, then it will be available with probability $p \in(0,1)$, and, otherwise, it will be unavailable.

As in period 1, in period 2, the (period-2) proposer decides whether to make a proposal, and the (period-2) receiver can veto the proposal. However, the set of the proposals that the proposer can make depends on whether $a_{1}$ is available. If $a_{1}$ is unavailable, then the proposer decides whether to propose $a_{2}$. If $a_{1}$ is available, then the proposer decides whether to make a proposal from an enlarged proposal set:

$$
\left\{\left\{a_{1}\right\},\left\{a_{2}\right\},\left\{\left\{a_{1}\right\},\left\{a_{2}\right\}\right\},\left\{a_{1}, a_{2}\right\}\right\}
$$

where $\left\{a_{t}\right\}$ denotes a proposal of alternative $a_{t},\left\{\left\{a_{1}\right\},\left\{a_{2}\right\}\right\}$ denotes a proposal of two alternatives, and $\left\{a_{1}, a_{2}\right\}$ denotes a proposal of two bundled alternatives. A proposal that bundles alternatives, $\left\{a_{1}, a_{2}\right\}$, differs from a proposal of two alternatives, $\left\{\left\{a_{1}\right\},\left\{a_{2}\right\}\right\}$. In the former case, the receiver must decide whether to veto both or neither alternative; while in the latter case, the receiver decides whether to veto each alternative separately.

Payoffs. Each period's alternative, $a_{t}$, has a known voter-welfare component $w \in$ $\mathbb{R}_{+}$and an ex-ante unknown partisan component $v_{t}$, which is distributed according a symmetric distribution $F$, i.e., $F(-v)=1-F(v)$ for all $v$. Payoffs are defined as follows. If $a_{t}$ passes, then player $j \in\{L, R, V\}$ receives a single-period payoff of $u_{j}\left(a_{t}\right)$, where

$$
u_{L}\left(a_{t}\right):=w-v_{t}, \quad u_{R}\left(a_{t}\right):=w+v_{t}, \quad u_{V}\left(a_{t}\right):=w .
$$

If no alternative is accepted, then all players receive a (normalized) payoff of zero from 
the status quo, i.e., $u_{j}(\emptyset)=0$ for all $j$. Thus, player $j$ 's payoffs are

$$
U_{j}=u_{j}\left(a_{1}\right) \mathbb{I}_{a_{1} \text { passed in period 1. }}+\delta\left(u_{j}\left(a_{1}\right) \mathbb{I}_{a_{1} \text { passed in period 2. }}+u_{j}\left(a_{2}\right) \mathbb{I}_{a_{2} \text { passed in period 2. }}\right) \text {, }
$$

where $\delta \in(0,1)$ is a discount factor.

We will say that an alternative $a_{t}$ is bipartisan if $\left|v_{t}\right|<w$ (i.e., $u_{L}\left(a_{t}\right)>0$ and $u_{R}\left(a_{t}\right)>0$ ); otherwise, we say that $a_{t}$ is divisive. In addition, we say that an alternative $a_{t}$ is more partisan than another alternative $a_{t}^{\prime}$ if either $v_{t}>v_{t}^{\prime}>0$ or $v_{t}<v_{t}^{\prime}<0$, where $v_{t}$ and $v_{t}^{\prime}$ are the partisan components of alternative $a_{t}$ and $a_{t}^{\prime}$, respectively.

Equilibrium: Our equilibrium concept is Subgame Perfect Equilibrium (SPE) henceforth equilibrium.

\section{Analysis}

We now study the parties' and voter's optimal strategy. We proceed backward; Section 3.1 characterizes the period-2 policy outcome, Section 3.2 characterizes the voter's decision, and Section 3.3 characterizes the period-1 policy outcome. To provide a benchmark for our results and the effect of policy bundling, Section 3.4 describes the equilibrium outcome of a modified version of our model where the proposer is unable to bundle policies.

\subsection{Period-2 policy outcomes}

In period 2, the receiver will accept a proposal whenever it provides them with a nonnegative payoff. The proposer anticipates the behavior of the receiver and will make a proposal that maximizes their payoff, while also ensuring that the receiver's payoff is non-negative. For ease of exposition, we characterize the period-2 policy outcomes with a sequence of lemmas (Lemmas 1-4) that cover four cases. 
Lemma 1 considers the case in which the period-1 alternative is unavailable ${ }^{13}$ as a proposal in period 2. In this case, the proposer simply decides whether to propose the period-2 alternative. Since the receiver will veto any proposal that provides them with a negative payoff, the period-2 alternative passes if and only if it is bipartisan.

Lemma 1 (Unavailable period-1 alternative) If the period-1 alternative is unavailable, then the period-2 alternative passes if and only if it is bipartisan, i.e., $v_{2} \in(-w, w)$.

We now consider cases in which the period-1 alternative is available as a proposal in period 2. In such cases, the proposer has an enlarged proposal set: they can propose each alternative individually or bundle both alternatives as a single proposal.

Lemma 2 considers the case in which the period-1 alternative is available and bipartisan. In this case, both proposer and receiver prefer that period- 1 alternative, $a_{1}$, pass and, hence, the policy outcome will include $a_{1}$. Similarly, if the period-2 alternative, $a_{2}$, is bipartisan, then the policy outcome will also include $a_{2} \cdot{ }^{14}$ However, when the period-2 alternative is divisive (i.e., it is not bipartisan), bundling the alternatives may allow the proposer to attain a higher payoff than otherwise possible. For example, suppose that the period-2 alternative is divisive such that it provides the receiver (proposer) with a negative (positive) payoff. This means that the receiver prefers that $a_{2}$ does not pass, while the proposer prefers that $a_{2}$ does pass. Nonetheless, by bundling the bipartisan alternative, $a_{1}$, with the divisive alternative, $a_{2}$, the proposer may be able to coerce the receiver to accept both alternatives since a bundled proposal forces the receiver to choose between accepting both alternatives or neither. Bundling will be effective in coercing the receiver when the receiver's negative payoff from the divisive alternative, $a_{2}$, is smaller than their positive payoff from the bipartisan alternative, $a_{1}$. Because the unpassed period- 1 alternative $a_{1}$ allows the proposer to attain a more favorable period-2 policy outcome - at the

\footnotetext{
${ }^{13}$ I.e., either the period-1 alternative passed in period 1, or it did not pass and is unavailable.

${ }^{14}$ In such cases, both the proposer and receiver are indifferent between proposing and accepting a proposal that bundles both alternatives, $\left\{a_{1}, a_{2}\right\}$, and a proposal that proposes both alternatives individually, $\left\{\left\{a_{1}\right\},\left\{a_{2}\right\}\right\}$.
} 
expense of the receiver - we say that the unpassed alternative provides leverage value to the proposer.

Lemma 2 (Available and bipartisan period-1 alternative) Suppose $R$ is the period-2 proposer. If the period-1 alternative is available and it is bipartisan, then the period-2 policy outcome is as follows:

(i) if $a_{2}$ is bipartisan, i.e., $v_{2} \in(-w, w)$, then $\left\{a_{1}, a_{2}\right\}$ or $\left\{\left\{a_{1}\right\},\left\{a_{2}\right\}\right\}$ is passed;

(ii) if $a_{2}$ is divisive such that $v_{2} \in\left(w, w+u_{L}\left(a_{1}\right)\right)$, then $\left\{a_{1}, a_{2}\right\}$ is passed;

(iii) otherwise, $\left\{a_{1}\right\}$ is passed. ${ }^{15}$

In Lemmas 3 and 4 , we consider the case in which the period-1 alternative is available and divisive. Lemma 3 focuses on the case where the period- 1 alternative is divisive such that it provides positive payoff to the proposer and a negative payoff to the receiver. Similar to the earlier lemmas, if the period- 2 alternative, $a_{2}$, is bipartisan, then both proposer and receiver prefer that $a_{2}$ pass and, hence, the policy outcome will include $a_{2}$. However, in the case focused on by Lemma 3 , the proposer prefers that the period-1 alternative, $a_{1}$, pass and, since it is divisive, policy bundling is required to coerce the receiver into accepting a proposal that includes $a_{1}$. The proposer will bundle the alternatives whenever the period-2 alternative is divisive and provides a relatively small negative payoff to the proposer, or the period-2 alternative is bipartisan and provides a relatively large positive payoff to the receiver.

Lemma 3 (Available and divisive period-1 alternative I) Suppose $R$ is the period-2 proposer and the period-1 alternative is available. If the period-1 alternative is divisive such that $u_{L}\left(a_{1}\right)<$ $0, u_{R}\left(a_{1}\right)>0$, then the period-2 policy outcome is as follows:

(i) if $a_{2}$ is bipartisan or divisive such that $v_{2} \in\left(-w-u_{R}\left(a_{1}\right), w+u_{L}\left(a_{1}\right)\right)$, then $\left\{a_{1}, a_{2}\right\}$ is passed;

${ }^{15}$ When $L$ is the period-2 proposer, the characterization is similar. In particular, the condition (ii) is modified such that $v_{2} \in\left(-w-u_{R}\left(a_{1}\right),-w\right)$. 
(ii) if $a_{2}$ is bipartisan such that $v_{2} \in\left(\max \left\{-w, w+u_{L}\left(a_{1}\right)\right\}, w\right)$, then $\left\{a_{2}\right\}$ is passed;

(iii) otherwise, no policy passes. ${ }^{16}$

Lemma 4 is similar to Lemma 3 but focuses on the case where the period- 1 alternative is divisive such that it provides negative payoff to the proposer and positive payoff to the receiver. The main conceptual difference between Lemma 3 and Lemma 4 is that in Lemma 4 the proposer prefers that the period- 1 alternative, $a_{1}$, does not pass and, hence, will never bundle $a_{1}$ with a bipartisan period-2 alternative; while in Lemma 3 , the proposer prefers that $a_{1}$ does pass and, hence, will bundle $a_{1}$ with a bipartisan - and sometimes even a divisive - period-2 alternative.

Lemma 4 (Available and divisive period-1 alternative II) Suppose $R$ is the period-2 proposer and the period-1 alternative is available. If the period-1 alternative is divisive such that $u_{L}\left(a_{1}\right)>0, u_{R}\left(a_{1}\right)<0$, then the period- 2 policy outcome is as follows:

(i) if $a_{2}$ is divisive such that $v_{2} \in\left(\max \left\{w,-u_{R}\left(a_{1}\right)-w\right\}, w+u_{L}\left(a_{1}\right)\right)$, then $\left\{a_{1}, a_{2}\right\}$ is passed;

(ii) if $a_{2}$ is bipartisan, i.e., $v_{2} \in(-w, w)$, then $\left\{a_{2}\right\}$ is passed;

(iii) otherwise, no policy passes. ${ }^{17}$

\subsection{The Voter's decision}

We now turn to the voter's decision. After observing the period-1 policy outcome, the voter elects one party to be the proposer for period 2. The voter's payoff is independent of an alternative's partisan component. Hence, their payoff is maximized by electing the

\footnotetext{
${ }^{16}$ When $L$ is the period-2 proposer and $u_{L}\left(a_{1}\right)<0, u_{R}\left(a_{1}\right)>0$, the characterization is similar to that in Lemma 4. In particular, condition (i) of Lemma 4 is modified such that $v_{2} \in\left(-w+u_{R}\left(a_{1}\right), \min \{-w, w+\right.$ $\left.\left.u_{L}\left(a_{1}\right)\right\}\right)$.

${ }^{17}$ When $L$ is the period-2 proposer and $u_{L}\left(a_{1}\right)>0, u_{R}\left(a_{1}\right)<0$, the characterization is similar to that in Lemma 3 . In particular, condition (ii) of Lemma 3 is modified such that $v_{2} \in\left(-w, \min \left\{w,-w-u_{R}\left(a_{1}\right)\right\}\right)$.
} 
party that, if elected, is likely to pass the most alternatives. If the period- 1 alternative passed in period 1, then the period-2 policy outcome is independent of the period-2 proposer's identity (Lemma 1). In this case, the voter will be indifferent between electing either party. However, if the period-1 alternative did not pass, then the voter prefers to elect the party that receives the smallest positive payoff from the period-1 alternative. ${ }^{18}$ When the period- 1 alternative is bipartisan, electing the party with the smallest payoff maximizes the probability of the period-2 proposer passing both alternatives. This is because the period-2 receiver values the unpassed alternative more than the proposer does and, hence, the proposer has more leverage over the receiver to pass divisive alternatives. On the other hand, if the period- 1 alternative, $a_{1}$, is divisive, then electing the party that prefers the $a_{1}$ to pass ensures that the period-2 proposer will pass $a_{1}$ whenever possible. Proposition 1 states this result.

Proposition 1 (Voter's behavior) At the end of period 1, if the period-1 alternative, $a_{1}$, did not pass and

(i) $a_{1}$ is bipartisan, then the voter will elect the party $j \in\{L, R\}$ such that $u_{j}\left(a_{1}\right)<u_{-j}\left(a_{1}\right)$

(ii) $a_{1}$ is divisive such that $\left|v_{1}\right| \in(w, 3 w)$, then the voter will elect the party $j \in\{L, R\}$ such that $u_{j}\left(a_{1}\right)>0$;

in all other cases, the voter will be indifferent between electing either party.

\subsection{The period-1 policy outcome}

We now turn to period 1 . In period 1, there is a single alternative that can be proposed, and both parties have veto power: the proposer, $L$, can "veto" the period- 1 alternative by delaying or refusing to propose the alternative, and the receiver, $R$, can reject any

\footnotetext{
${ }^{18}$ If the period- 1 alternative, $a_{1}$, is divisive with a partisan component that is sufficiently large, then the voter will only have a weak preference to elect the party that receives a positive payoff from passing $a_{1}$.
} 
proposal. Thus, the identity of the period-1 proposer and receiver are of no consequence in our model.

Proposition 2 states that, in period 1, the period-1 alternative never passes if it is divisive. If the period-1 alternative is divisive, then, by definition, one party will receive a negative payoff from passing the alternative. This party will have a strict incentive to prevent the alternative from passing. If the alternative passes, then this party will experience an immediate negative payoff and, regardless of which party is elected for period 2, the period-2 alternative will pass if and only if it is bipartisan (Lemma 1). If the alternative does not pass, then this party will avoid an immediate negative payoff. In this case, the unpassed alternative may turn out to be unavailable in future, in which case the party avoids the negative payoff entirely, or the unpassed alternative is available. If it is available, then in the worst case the period-2 proposer will bundle this alternative with a bipartisan period-2 alternative. However, due to parties discounting future payoffs, this outcome is still preferred to the outcome that follows from the period- 1 alternative passing in period 1 .

Proposition 2 (Period-1 outcome with a divisive alternative) If the period-1 alternative is divisive, then it never passes.

We now consider the decision that parties face in period 1 when the period- 1 alternative is bipartisan. To make the intuition precise, suppose that party $L$ receives higher (positive) payoff than party $R$ from the period-1 alternative, i.e., $0<u_{R}\left(a_{1}\right)<u_{L}\left(a_{1}\right)$. In this case, party $L$ is electorally disadvantaged: if the period- 1 alternative does not pass, then the party $R$ will be elected with certainty (Proposition 11). Thus, if the period- 1 alternative does not pass, then either the unpassed alternative will be unavailable and, in the future period, only bipartisan period-2 alternatives will pass, or the unpassed alternative will be available and, hence, will be used as leverage by the proposer (party $R$ ) at party $L$ 's expense. On the other hand, if the period-1 alternative passes, then they receive an immediate positive payoff and, in the future period, only bipartisan period-2 alternatives 
will pass. Thus, the electorally-disadvantaged party (in this case, party $L$ ) prefers that the period-1 alternative passes and, hence, will never veto or delay a proposal. ${ }^{19}$ Lemma 5 states this result.

Lemma 5 (Period-1 outcome with a bipartisan alternative I) If the period-1 alternative is bipartisan, then the party with higher payoff (i.e., $j \in\{L, R\}: u_{-j}\left(a_{1}\right)<u_{j}\left(a_{1}\right)$ ) never vetoes or delays a proposal.

Continuing from the above paragraph, we now consider the decision facing party $R$. Party $R$ is electorally advantaged: if the period- 1 alternative does not pass, then they will be elected with certainty. Furthermore, the party $L$ will never veto or delay a proposal (Lemma 5); thus, party $R$ can unilaterally decide whether the period-1 alternative passes. This leads to the following trade-off. If party $R$ allows the period- 1 alternative to pass, then they will attain an immediate positive payoff, but in the future - regardless of which party is elected - only bipartisan period-2 alternatives will pass. The expected payoff to party $R$ in this instance is

$$
u_{R}\left(a_{1}\right)+\delta \int_{-w}^{w}\left(w+v_{2}\right) d F\left(v_{2}\right)
$$

Alternatively, if party $R$ does not allow the period- 1 alternative to pass, then they will be elected as the proposer in period 2. With probability $(1-p)$, the unpassed period-1 alternative will be unavailable as a proposal in the future, and only bipartisan period2 alternatives will pass. However, if the period-1 alternative turns out to be available, then the period-1 alternative will pass in period 2. In addition, it will provide leverage that allows party $R$ to pass not only bipartisan period-2 alternatives but also divisive

\footnotetext{
${ }^{19}$ To be precise, they will never veto or delay if their action is pivotal for the period-1 outcome.
} 
alternatives that benefit party $R$. The expected payoff to party $R$ in this instance is

$$
\begin{aligned}
\delta(1-p) \int_{-w}^{w}\left(w+v_{2}\right) d F\left(v_{2}\right)+\delta p\left(u_{R}\left(a_{1}\right)\right. & +\int_{-w}^{w}\left(w+v_{2}\right) d F\left(v_{2}\right) \\
& \left.+\int_{w}^{w+u_{L}\left(a_{1}\right)}\left(w+v_{2}\right) d F\left(v_{2}\right)\right) .
\end{aligned}
$$

Thus, party $R$ will allow the (bipartisan) period-1 alternative to pass if and only the difference between (1) and (2) is non-negative, i.e.,

$$
\Phi_{R}:=\underbrace{(1-\delta p) u_{R}\left(a_{1}\right)}_{\text {Net gain from passing } a_{1} \text { today }}-\underbrace{\delta p \int_{w}^{w+u_{L}\left(a_{1}\right)}\left(w+v_{2}\right) d F\left(v_{2}\right)}_{\text {Net gain from vetoing } a_{1} \text {, i.e., leverage value. }} \geq 0
$$

Notice that second term's integral ranges over period-2 alternatives that have a partisan component, $v_{2}$, such that the period-2 alternative is divisive, favors party $R$, but also ensures that party $L$ is willing to accept a proposal that bundles both alternatives. That is, the second term captures the leverage value of the unpassed alternative. Proposition 3 formalizes this result.

Proposition 3 (Period-1 outcome with a bipartisan alternative II) If the period-1 alternative is bipartisan, then it passes if and only if $\Phi_{j} \geq 0$, where $j \in\{L, R\}: u_{j}\left(a_{1}\right)<u_{-j}\left(a_{1}\right)$ and

$$
\Phi_{j}=\underbrace{(1-\delta p) u_{j}\left(a_{1}\right)}_{\text {Net gain from passing } a_{1} \text { today }}-\underbrace{\delta p \begin{cases}\int_{w}^{w+u_{L}\left(a_{1}\right)}\left(w+v_{2}\right) d F\left(v_{2}\right), & \text { if } j=R \\ \int_{-w-u_{R}\left(a_{1}\right)}^{-w}\left(w-v_{2}\right) d F\left(v_{2}\right), & \text { if } j=L .\end{cases} }_{\text {Net gain from vetoing } a_{1}, \text { i.e., leverage value. }}
$$

Lemmas 14 and Propositions $1-3$ characterize the equilibrium behavior of the parties and the voter. We remark that, with exception of a set of measure zero, all equilibria provide equal payoffs to the voter and each party, and the policy outcome for each period is unique. For brevity's sake, we omit a proof. 


\subsection{A modified model without policy bundling}

Before proceeding to the next section, it will be useful to describe the equilibrium of a modified version of our model where there is no policy bundling. In this modified model, the equilibrium is trivial. The parties behave myopically: in each period $t$, an alternative passes if and only if it is bipartisan. Proposition 4 states this result.

Proposition 4 (Policy outcome without policy bundling) Suppose the proposer cannot bundle policies. In each period $t$, the period-t alternative $a_{t}$ passes if and only if it is bipartisan.

\subsection{Gridlock in equilibrium}

Gridlock refers to situations where policy fails to pass in a timely manner. Formally, we say gridlock occurs if alternative $a_{t}$ does not pass in period $t$. Proposition 2 shows that gridlock occurs in period 1 whenever the alternative is divisive; this aligns with the notion of a "gridlock interval" (Romer and Rosenthal, 1978). However, this is not the only situation in which gridlock arises. Proposition 3 shows that gridlock can occur even when an alternative is bipartisan. In this situation, gridlock arises due to the dynamic environment and the leverage incentive: by vetoing an alternative today, a party attains leverage that can be used in the future via policy bundling.

It will be useful to distinguish between the two forms of gridlock described above, which we call preference-based and leverage-based gridlock, respectively. Definition 1 provides a formal definition.

Definition 1 (Preference-based gridlock and leverage-based gridlock) We say there is gridlock in period $t$ when the period-t alternative $a_{t}$ does not pass in period $t$. We say the gridlock is preference-based gridlock if $a_{t}$ is divisive; otherwise, we say it is leverage-based gridlock.

We now consider the effect of policy bundling on gridlock. We do so by comparing the probability that gridlock arises in our model (where policy bundling is allowed) with 
the probability that gridlock arises in the modified model without policy bundling (as per Proposition 44. Proposition 5 says that policy bundling has an ambiguous effect on the frequency of gridlock. In the final period, policy bundling decreases gridlock; however, in the first period, policy bundling increases gridlock.

Proposition 5 (Policy bundling and gridlock frequency) Relative to the modified model without policy bundling, policy bundling causes more frequent gridlock in period 1 but less frequent gridlock in period 2. In particular,

(i) in period 1, policy bundling has no effect on the frequency of preference-based gridlock but increases the frequency of leverage-based gridlock;

(ii) in period 2, policy bundling has no effect on the frequency of leverage-based gridlock but decreases the frequency of preference-based gridlock.

Intuitively, policy bundling makes gridlock less likely in the final period. This follows because policy bundling allows the proposer to combine alternatives that would not pass on their own. This captures the conventional wisdom surrounding policy bundling: policy bundling reduces gridlock by facilitating compromise (Krutz, 2000, 2001; Sinclair. 1997). While confirming the conventional wisdom, Proposition 5 also shows that this wisdom is incomplete. Policy bundling generates more frequent gridlock in the first period. This occurs because policy bundling creates an incentive for one party to gridlock bipartisan alternatives in pursuit of leverage in future. However, without policy bundling there is no leverage incentive, parties behave myopically and, ergo, leverage-based gridlock never occurs.

\section{Leverage-based gridlock comparative statics}

We now derive conditions that make gridlock more likely to occur. Our focus is on comparative statics relating to leverage-based gridlock, which arises only in period 1 and is a 
novel feature of our policy bundling model. Proposition 6 provides an interim comparative static: gridlock is more likely to occur when the period-1 alternative is more partisan.

Proposition 6 (Partisanship and gridlock) Leverage-based gridlock and gridlock are more likely to occur as the period-1 alternative becomes more partisan.

Proposition 6 is intuitive. Suppose the period-1 alternative is bipartisan. In such cases, only the party with the smallest payoff has an incentive to veto the alternative since they will be elected if the alternative fails to pass. However, vetoing the alternative is costly since future payoffs are discounted and the alternative will not be passed today. As the alternative becomes more partisan, the smallest-payoff (highest-payoff) party's payoff decreases (increases). This leads the smallest-payoff party to have a greater incentive to engage in gridlock: delaying the alternative is now less costly, and the leverage benefit has increased since they will be able to pass even more divisive alternatives in the future. Furthermore, if the alternative becomes sufficiently partisan, then it will no longer be bipartisan and, instead, will be divisive. In this case, the alternative never passes.

We now consider ex-ante comparative statics. Proposition 7 says that leverage-based gridlock is more likely to occur if unpassed alternatives are more likely to be available as proposals in future or if the future is discounted at a lower rate. Since unpassed alternatives are more likely to be available in the future during times of economic stability, the proposition suggests that economic stability may be associated with more frequent leverage-based gridlock.

Proposition 7 (Basic comparative statics) Leverage-based gridlock is more likely to occur as

(i) the probability that an unpassed alternative is available increases ( $\uparrow$ ), and

(ii) the future is discounted at a lower rate $(\uparrow \delta)$.

These same comparative statics hold (trivially) for preference-based gridlock. 
When a party engages in leverage-based gridlock they face two costs. First, the unpassed (bipartisan) alternative may be unavailable as proposal in the future, in which case they forgo any payoff associated with the alternative and there is no leverage benefit. Second, there is a cost of delay because future payoffs are discounted. If alternatives are more likely to be available in the future, then the first cost is lower. If the future is discounted at a lower rate, then the second cost is lower. Thus, in each case, a party will face a stronger incentive to induce gridlock, and this increases the likelihood of leverage-based gridlock..$^{20}$

Lastly, we consider the effect of polarization on the frequency of leverage-based gridlock. We measure the level of polarization between the parties by the likelihood that each period's alternative will include a large partisan component, $\left|v_{t}\right|$. More formally, let $v_{t}^{F}$ and $v_{t}^{G}$ be two random variables that correspond to the partisan component of each period's alternative under (symmetric) distributions $F$ and $G$, respectively. We will say that there is greater polarization under $F$, compared to $G$, if $\left|v_{t}^{F}\right|$ first-order stochastically dominates $\left|v_{t}^{G}\right|{ }^{21,22}$ This captures intuitive features of polarization: when polarization is higher, alternatives are less likely to be bipartisan, and divisive alternatives are likely to include larger partisan components.

Since polarization increases the likelihood of divisive alternatives and divisive alternatives never pass in period 1, it is immediate that polarization increases preferencebased gridlock in period 1 . However, Proposition 8 says that polarization can have a non-monotonic effect on leverage-based gridlock and period-1 gridlock.

Proposition 8 (Polarization and gridlock) Polarization increases the frequency of preferencebased gridlock in period 1 but can have a non-monotonic effect on the frequency of leverage-based

\footnotetext{
${ }^{20}$ This comparative static holds trivially for preference-based gridlock since, in period-1, a divisive alternative never passes and, in period 2, the parties' strategies are independent of $p$ and $\delta$.

${ }^{21}$ Due to $F$ and $G$ being symmetric distributions, this condition reduces to $F(v) \leq G(v)$ for all $v \geq 0$, with strict inequality for some $v \geq 0$.

${ }^{22}$ This condition can be equivalently stated in terms of the difference between party payoffs since $\left|v_{t}\right|=$ $\frac{1}{2}\left|u_{R}\left(a_{t}\right)-u_{L}\left(a_{t}\right)\right|$ for all $a_{t}$.
} 
gridlock. Furthermore, polarization can have a non-monotonic effect on the frequency of gridlock in period 1 .

Polarization affects not only the likelihood that an alternative is divisive or bipartisan, but also the leverage incentive of parties. When polarization is sufficiently low, there is no preference- or leverage-based gridlock. Alternatives are always bipartisan and, hence, there is no leverage incentive. When polarization is intermediate, gridlock may reach its highest levels. Alternatives will often be divisive and, hence, fail to pass. But even bipartisan alternatives may fail to pass. This is because parties will anticipate that future alternatives are likely to be divisive and will need leverage to pass. In some instances, a further increase in polarization will reduce gridlock. This occurs if, holding all else equal, divisive alternatives become more partisan such that - even with the leverage provided by an unpassed bipartisan alternative - policy bundling will be ineffective in coercing the receiver to accept both alternatives. Thus, the increase in polarization removes the leverage incentive of parties and, hence, there will be no leverage-based gridlock: all bipartisan alternatives will pass in period 1 . This leads to a reduction in the frequency of leverage-based gridlock and period-1 gridlock.

\section{Voter welfare and efficient gridlock}

We now consider the effect of gridlock on voter welfare and ask: "Can gridlock be welfareimproving for the voter? And, if so, when?" Given an alternative $a_{t}$ and the equilibrium behaviors of the parties, we say gridlock is efficient in period $t$ if the voter receives a higher payoff when $a_{t}$ does not pass than when it does; otherwise, we say it is inefficient.

It is immediate that gridlock is never efficient in period 2. However, Proposition 9 says that, under certain conditions, gridlock will be efficient in period 1 . This is because when a present-day alternative fails to pass it can lead to more alternatives passing in the future. 
Proposition 9 (Efficient gridlock) Leverage-based gridlock is always efficient if

$$
F(2 w)-F(w)>1 /(\delta p)-1
$$

is never efficient if $F(3 w)-F(w)<1 /(\delta p)-1$; otherwise, it is sometimes efficient.

Leverage-based gridlock is always efficient when the future is discounted at low rate, unpassed alternatives are likely to be available in the future, and divisive alternatives are likely to provide only small negative payoffs. One interpretation of this condition is that leverage-based gridlock is always efficient if there is economic stability and only intermediate levels of polarization. This result is intuitive. When alternatives are likely to be available in the future and disagreement between the parties is moderate, it is likely that the unpassed alternative will provide sufficient leverage to pass future alternatives that are divisive and otherwise would not pass.

In equilibrium, gridlock occurs in excess. Whenever gridlock is efficient, it occurs as an equilibrium outcome. However, gridlock can also arise in equilibrium even when it is inefficient. Proposition 10 states this result.

Proposition 10 (A state of excess gridlock) If leverage-based gridlock is efficient, then leveragebased gridlock occurs in equilibrium. However, in equilibrium, leverage-based gridlock can also occur when it is inefficient. ${ }^{23}$

Consider an instance where the period- 1 alternative is bipartisan. Gridlock is efficient whenever the cost of delaying the present-day proposal is small, and the leverage value is likely to be sufficient in passing future alternatives that are divisive and otherwise would not pass. Recall that, in equilibrium, the party with the smallest positive payoff will unilaterally decide whether to pass the period- 1 alternative and, in doing so, the party

\footnotetext{
${ }^{23}$ The statement focuses on leverage-based gridlock; however, the statement extends trivially if, in addition, we consider preference-based gridlock. This is because gridlock always occurs if one of the parties receives a negative payoff from passing the period- 1 alternative.
} 
trades-off the cost of delay with the benefit of leverage. This trade-off is similar to the trade-off faced by the voter in calculating whether gridlock is efficient. However, for the party, the cost of delay is smaller and the benefit of leverage is larger. Hence, whenever the voter finds gridlock to be preferable (i.e., efficient), so too will the party. This follows because the party's payoff from passing the period-1 alternative is necessarily lower than the voter's, and the party's future payoff from passing divisive alternatives that have a favorable partisan component is higher than the voter's payoff.

Proposition 10 aligns with the conventional wisdom that - despite gridlock sometimes being efficient - gridlock occurs too often and is welfare-reducing. This also provides a justification for why constitutional reforms typically aim at reducing inefficient gridlock, rather than increasing efficient gridlock.

Although parties often bear the blame for the excessive levels of gridlock, we show that the voter is at least partially to be blamed. When the present-day alternative is bipartisan, the (forward-looking) voter rationally elects the party with the smallest payoff if the proposal does not pass. This increases the incentive of the electorally-advantaged party to engage in gridlock. For this electorally-advantaged party, inducing gridlock comes at the cost of delay but also the benefit of leverage when elected in the future. However, if the voter is not forward-looking, then there need not be any electorally-advantaged party. In this case, there is less incentive for parties to engage in gridlock since there is now a risk from inducing leverage: if the other party is elected, the unpassed alternative may be used as leverage against the party that induced gridlock.

Proposition 11 formalizes the above logic and shows the extent to which a voter with commitment power can discipline the parties and avoid inefficient gridlock. When the voter has commitment power, inefficient leverage-based gridlock can be completely eradicated. However, commitment power has no effect on the frequency of preference-based gridlock. The basic idea underlying this result is that if the voter commits to punishing a vetoing party by electing the opposing party, then a party never attains a leverage-benefit 
from inducing gridlock.

Proposition 11 (Voter commitment power) If the voter has commitment power, then leveragebased gridlock occurs in equilibrium if and only if it is efficient. However, commitment power has no effect on the frequency of preference-based gridlock and, hence, both efficient and inefficient preference-based gridlock will occur.

With commitment power, the voter is able to prevent inefficient leverage-based gridlock. This is achieved by following a "blame-game" strategy (à la Groseclose and McCarty (2001); Smith (1988)) whenever the present-day alternative is bipartisan and gridlock is inefficient. In particular, if a party vetoes a proposal, then the voter elects the other party; if both parties veto a proposal, then the voter elects one party by default (say, party $L$ ). This voting strategy ensures that there is a unique equilibrium in the bargaining game where neither party gridlocks a bipartisan alternative. ${ }^{24}$ However, when the alternative is divisive, the voter - even with commitment power - cannot prevent preference-based gridlock.

\section{Constitutional amendments and policy bundling}

We now turn to the long-running debate of whether policy bundling should be removed from Congress via constitutional reform. The debate focuses on two reforms: the line-item veto (LIV) and the single-subject rule (SSR). The LIV allows the President or Governor to reject sections of a proposal; while, the SSR makes the bundling of unrelated policies unconstitutional (Townsend, 1985).

In our model, both reforms are equivalent in equilibrium. In particular, the equilibrium outcome coincides with the modified version of our model without policy bundling (as discussed in Proposition 44. ${ }^{25}$ Thus, we analyze the welfare effects of a SSR or LIV by

\footnotetext{
${ }^{24}$ We note that the empirical literature is divided on whether voter-behavior is retrospective (see references within the introduction).

${ }^{25}$ Focusing on a non-dynamic setting, Brown (2012) also reaches this conclusion.
} 
comparing the voter's expected payoff under this modified model (without policy bundling) and the benchmark model (with policy bundling).

We show that the reforms present a trade-off. A benefit of the LIV/SSR is that it avoids inefficient leverage-based gridlock. However, there are two costs. The LIV/SSR prevents efficient leverage-based gridlock and prevents period-2 compromises. These trade-offs are entangled. Implementing the LIV/SSR is always costly for the voter because it prevents period-2 compromises, but it may be beneficial if inefficient leverage-based gridlock occurs often. However, when parties face strong incentives to engage in inefficient leverage-based gridlock - making the LIV/SSR more beneficial to the voter - it must be that leverage-based gridlock rarely occurs, which reduces the benefit of the LIV/SSR to the voter.

Proposition 12 says that under certain conditions policy bundling is optimal. When alternatives are unlikely to be bipartisan or alternatives are likely to be divisive such that they provide one party with only small negative payoffs (e.g., intermediate levels of polarization), then policy bundling will be optimal.

Proposition 12 (LIV/SSR not optimal) LIV/SSR are not optimal if either $F(w)-F(-w) \approx 0$ or $F(2 w)-F(w)>1 /(\delta p)-1$.

The first condition in Proposition 12 corresponds to the case where leverage-based gridlock rarely occurs, but the voter benefits from policy bundling because it facilitates compromises. The second condition corresponds to the case where leverage-based gridlock may occur but is always efficient — this is the same condition introduced in Proposition 9 .

Unsurprisingly, policy bundling is not always optimal. Proposition 13 states that, for some parameter ranges, the LIV/SSR will be optimal.

Proposition 13 (LIV/SSR optimal) For some parameter ranges, LIV/SSR is optimal. 
The proof of Proposition 13 requires the construction of a very specific family of distribution functions. The key idea is that policy bundling will be suboptimal if the distribution of payoffs make leverage-based gridlock inefficient, and leverage-based gridlock occurs frequently. This requires that bipartisan alternatives often provide payoffs that leave one party close to indifferent about whether the alternative passes.

\section{Discussion and Empirical Implications}

In this paper we introduced a dynamic model of bargaining with policy bundling. We argued that the prevailing wisdom that policy bundling reduces gridlock by facilitating compromises is incomplete. In particular, we showed that policy bundling — in addition to facilitating compromise - generates dynamic concerns and a "leverage" incentive that increases gridlock.

This additional leverage incentive leads to new insights. Gridlock can arise in equilibrium even when both parties agree that an alternative is preferred to the status-quo (i.e., bipartisan). Gridlock is more likely to occur when present-day alternatives are more partisan or more likely to be available in the future (e.g., during periods of economic stability), and polarization can have a non-monotonic effect on the frequency of gridlock. We also showed that, from the voter's perspective, gridlock occurs too often in equilibrium, and the voter's lack of commitment power is at least partially to be blamed for this state of excess gridlock. Our results also contribute insights for the debate of whether policy bundling should be removed from Congress via constitutional reform.

Our results have a number of empirical implications. First, the phenomenon of leverage-based gridlock suggests that traditional measures of ideology based on roll-call voting records (e.g., NOMINATE methods of Poole and Rosenthal (1985)) will overstate ideological disagreement between parties. This is because a party may vote against (or prevent a vote for) legislation, not because they are ideologically opposed to it, but be- 
cause doing so leads to greater policy gains in the future. That is, roll call-voting records will confound ideological disagreements between legislators with their dynamic concerns.

Second, we predict that gridlock will be more frequent during periods of economic stability. Economic stability makes an unpassed alternative more likely to be a viable alternative in the future. This increases the incentive for an electorally-advantaged party to engage in gridlock, since it simultaneously decreases the cost of delaying alternatives and increases the expected leverage benefits. In other words, economic stability strengthens the dynamic concerns of the parties and leads them to behave less myopically.

These two predictions provide a novel explanation for why polarization, as measured via NOMINATE, has increased rapidly since the 1980s (Barber and McCarty, 2015). The 1980s marked the beginning of the Great Moderation, a period of economic stability, leading to more frequent leverage-based gridlock and, hence, overstated measures of polarization. This may also explain why polarization within Congress compared to that within the public is more pronounced (Hetherington, 2001).

Finally, our results show that gridlock and polarization can have a non-monotonic relationship. This presents a challenge for empirical research that typically assumes a linear relationship. It also shows that direct measures of gridlock may fail to capture ideological disagreement between legislators. 


\section{References}

Abreu, Dilip and Faruk Gul, “Bargaining and Reputation," Econometrica, 2000, 68 (1), 85-117.

Acharya, Avidit and Juan Ortner, "Paths to the Frontier," Working paper, 2018.

Austin-Smith, David, Wioletta Dziuda, Bård Harstad, and Antoine Loeper, "Gridlock and Inefficient Policy Instruments," Theoretical Economics, 2019.

Barber, Michael and Nolan McCarty, "Causes and Consequences of Polarization," in "Solutions to Political Polarization in America," Cambridge: Cambridge University Press, 2015.

Binder, Sarah A., Statemate: Causes and consequences of legislative gridlock, Brookings Press, 2003.

Binder, Sarah A., "Polarized We Govern?," Brookings Institution, 2014.

Brady, David W. and Craig Volden, Revolving Gridlock: Politics and Policy from Carter to Clinton, Westview Press, 1998.

Brown, Adam R., “The Item Veto's Sting," State Politics E Policy Quarterly, 2012, 12 (2), 183-203.

Buchanan, James M. and Gordon Tullock, The Calculus of Consent, Ann Arbor, 1962.

Callander, Steven, "Searching for good policies," American Political Science Review, 2011, $105(4), 643-662$.

Callander, Steven and Gregory J. Martin, "Dynamic Policymaking with Decay," American Journal of Political Science, 2017, 61 (1), 50-67.

Callander, Steven and Gregory J. Martin, "Policy Decay and Political Competition," Working Paper, 2020. 
Cameron, Charles and Nolan McCarty, "Models of Vetoes and Veto Bargaining," Annual Review of Political Science, 2004, 7, 409-435.

Casas, Andreu, Matthew J. Denny, and John Wilkerson, "More Effective Than We Thought: Accounting for legislative hitchhikers reveals a more inclusive and productive lawmaking process," The American Political Science Review, 2020, 64 (1), 5-18.

Chakraborty, Archishman and Rick Harbaugh, "Cheap talk comparisons in multi-issue bargaining," Economics Letters, 2003, 78 (3), 357-363.

Chen, Ying and Hülya Eraslan, "Information loss in bundled bargaining," Journal of Theoretical Politics, 2013, 25 (3), 338-362.

Chen, Ying and Hülya Eraslan, "Rhetoric in legislative bargaining with asymmetric information," Theoretical Economics, 2014, 9, 483-513.

Dziuda, Wioletta and Antoine Loeper, "Dynamic Collective Choice with Endogenous Status Quo," Journal of Political Economy, 2016, 124 (4), 1148-1186.

Elinder, Mikael, Henrik Jordahl, and Panu Poutvaara, "Promises, policies and pocketbook voting," European Economic Review, 2015, 75, 177-194.

Gilbert, Michael D., "Single Subject Rules and the Legislative Process," University of Pittsburgh Law Review, 2006, 67, 803-870.

Groseclose, Tim and Nolan McCarty, "The Politics of Blame: Bargaining before an Audience," American Journal of Political Science, 2001, 45 (1), 100-119.

Hetherington, Marc J., "Resurgent Mass Partisanship: The Role of Elite Polarization," American Political Science Review, 2001, 95 (3), 619-631.

Jackson, Matthew O. and Boaz Moselle, "Coalition and Party Formation in a Legislative Voting Game," Journal of Economic Theory, 2002, 103, 49-87. 
Krehbiel, Keith, "Institutional and Partisan Sources of Gridlock: A Theory of Divided and Unified Government," Journal of Theoretical Politics, 1996, 8, 7-40.

Krutz, Glen S., "Getting around Gridlock: The effect of omnibus utilization on legislative productivity," Legislative Studies Quarterly, 2000, 25 (4), 533-549.

Krutz, Glen S., "Tactical Maneuvering on Omnibus Bills in Congress," American Journal of Political Science, 2001, 45 (1), 210-223.

Lieberman, Joseph I., “A bipartisan renaissance in the making,” The Hill, January 2020.

Lowrey, Annie, Nathaniel Popper, and Nelson D. Schwartz, "Gridlock Has Cost U.S. Billions, and the Meter Is Still Running," The New York Times, October 2013.

MacKuen, Michael B., Robert S. Erikson, and James A. Stimson, "Peasants or Bankers? The American Electorate and the U.S. Economy," The American Political Science Review, $1992,86(3), 587-611$.

Masket, Seth, "Political polarization is not a driver of gridlock at the state level," Pacific Standard, May 2019.

McCarty, Nolan, "Presidential reputation and the veto," Economics and Politics, 1997, 9, $1-27$.

Nelson, Louis, "Trump, unhappy with omnibus bill, calls on Congress to reinstate lineitem veto," Politico, March 2018.

Norpoth, Helmut, "Presidents and the Prospective Voter," The Journal of Politics, 1996, 58 (3), 776-792.

Patty, John W., "Signaling through Obstruction," American Journal of Political Science, 2016, 60 (1), 175-189. 
Poole, Keith T. and Howard Rosenthal, "A Spatial Model for Legislative Roll-Call Analysis," American Journal of Political Science, 1985, 29, 357-384.

Rivlin, Alice, "Democrats have a major policy dilemma with new Congress," The Hill, November 2018.

Romer, Thomas and Howard Rosenthal, "Political Resource Allocation, Controlled Agendas, and the Status Quo," Public Choice, 1978, 33 (4), 27-43.

Sinclair, Barbara, Unorthodox Lawmaking: New Legislative Processes in the U.S. Congress, Washington, DC: CQ Press, 1997.

Smith, Hendrick, The Power Game: How Washington works, New York: Ballantine Books, 1988.

Townsend, Nancy J., "Single Subject Restrictions as an alternative to the line-item veto," Notre Dame Journal of Law, Ethics, \& Public Policy, 1985, 1 (2), 227-258.

Weingast, Barry R. and William J. Marshall, "The Industrial Organization of Congress; or, Why Legislatures, Like Firms, Are Not Organized as Markets," Journal of Political Economy, 1988, 96 (1), 132-163. 


\section{A Extensions}

In this section, we discuss some extensions of our baseline model from Section 2 For brevity's sake, our discussion is informal.

Electoral benefits. Political parties are likely motivated not only by legislative outcomes, per the baseline model, but also by the prospect of holding office. Our model can be extended to incorporate such electoral benefits. Suppose that, in addition to the payoffs specified in the baseline model, parties receive an additive (electoral benefit) payoff of $K_{t}>0$ if they are the period-t proposer. The introduction of electoral benefit increases the likelihood of leverage-based gridlock relative to the baseline model and leads to further reductions in voter welfare due to the higher frequency of inefficient gridlock. This follows because, absent electoral benefits, the party that induces leverage-based gridlock trades off the cost of delaying a proposal with the benefit of having leverage once they are elected for the future period. However, when electoral benefits are present, there is an additional benefit of generating gridlock since they will receive electoral benefits from being elected. ${ }^{26}$

Uncertain electoral outcomes: With exception of voter-indifference, election outcomes in the baseline model are deterministic (see Proposition 1). However, in reality election outcomes often feature some level of uncertainty. Uncertain electoral outcomes can be incorporated into our baseline model by introducing a valence shock to the voter's payoff function. ${ }^{27}$ Although our main insights continue to hold, valence shocks lead to a decrease in the likelihood of leverage-based gridlock relative to the baseline model. This is because, with deterministic electoral outcomes, the party that induces leverage-based gridlock trades off the cost of delaying a proposal with the benefit of having extra lever-

\footnotetext{
${ }^{26}$ Formally, this can be seen by noting that, in this extension of the model, the gridlock condition $\Phi_{j}<0$ in Proposition 3 changes to $\Phi_{j}-K_{2}<0$.

${ }^{27}$ For example, suppose that, in addition to the payoffs specified in the baseline model, the voter receives an additive payoff of $\gamma \in \mathbb{R}$ from electing party $R$. The valence parameter $\gamma$ is distributed according to some symmetric distribution $G$ and is realized after the period-1 policy outcome but before the voter's electoral decision.
} 
age once elected. However, when electoral outcomes are uncertain, there is an additional cost: if they are not elected in the future, then this extra leverage may be used against them, which leads to lower future payoffs. ${ }^{28}$

\section{B Omitted proofs}

Proof of Lemma 1. Assume party $R$ is the proposer in period 2, and suppose $a_{1}$ is not available as a proposal. ${ }^{29}$ If $a_{2}$ is bipartisan, i.e., $v_{2} \in(-w, w)$, then $u_{L}\left(a_{2}\right), u_{R}\left(a_{2}\right)>0$. Thus, party $R$ maximizes their payoff by passing $a_{2}$, and party $L$ will accept this proposal since it provides positive payoff. On the other hand, if $a_{2}$ is divisive, i.e., $v_{2} \notin(-w, w)$, then either $u_{L}\left(a_{2}\right)<0$ or $u_{R}\left(a_{2}\right)<0$. In the former case, party $L$ will not accept $a_{2}$ if it is proposed; in latter case, party $R$ optimally will not propose the alternative. Thus, $a_{2}$ will not be passed. That is, $a_{2}$ passes if and only if it is bipartisan.

Proof of Lemma 2. Assume party $R$ is the proposer in period 2, and suppose $a_{1}$ is available and bipartisan, i.e., $u_{L}\left(a_{1}\right), u_{R}\left(a_{1}\right)>0 .{ }^{30}$

If $a_{2}$ is bipartisan, i.e., $v_{2} \in(-w, w)$, then $u_{L}\left(a_{2}\right), u_{R}\left(a_{2}\right)>0$. Thus, $R$ maximizes their payoff by passing both alternatives, and party $L$ will accept a proposal of both alternatives (regardless of whether the two proposals are bundled) since it provides a positive payoff.

If $a_{2}$ is divisive such that $v_{2} \in\left(w, w+u_{L}\left(a_{1}\right)\right)$, then $u_{L}\left(a_{2}\right)<0, u_{R}\left(a_{2}\right)>0$. Thus, $R$ maximizes their payoff by passing both alternatives. If both alternatives are bundled, party $L$ receives a non-negative payoff since

$$
u_{L}\left(a_{1}\right)+u_{L}\left(a_{2}\right)=u_{L}\left(a_{1}\right)+w-v_{2}>0
$$

when $v_{2} \in\left(w, w+u_{L}\left(a_{1}\right)\right)$.

\footnotetext{
${ }^{28}$ This extension can also incorporate party favoritism by assuming that the valence shock is asymmetrically distributed. Party favoritism increases (reduces) the incentive for the favored (unfavored) party to engage in leverage-based gridlock.

${ }^{29}$ When $L$ is the proposer, the result is identical and the arguments are similar.

${ }^{30}$ When $L$ is the proposer, the result and arguments are similar (see Footnote 15 .
} 
If $a_{2}$ is divisive such that $v_{2} \notin\left(-w, w+u_{L}\left(a_{1}\right)\right)$, then $u_{L}\left(a_{1}\right)+u_{L}\left(a_{2}\right)<0$ or $u_{R}\left(a_{2}\right)<$ 0 . In the former case, $R$ maximizes their payoff by passing both alternatives; however, $L$ receives a negative payoff if both alternatives pass and, hence, $R$ cannot pass both alternatives. Furthermore, $R$ cannot pass $a_{2}$ as a singular proposal since it provides party $L$ with a negative payoff. As a result, party $R$ maximizes their payoff, among proposals that party $L$ will accept, by proposing only the bipartisan alternative, $a_{1}$.

Proof of Lemma 3. Suppose $a_{1}$ is available and divisive such that $u_{L}\left(a_{1}\right)<0, u_{R}\left(a_{1}\right)>0$, and assume that party $R$ is the proposer in period $2 .{ }^{31}$

If $a_{2}$ is bipartisan or divisive such that

$$
v_{2} \in\left(-w-u_{R}\left(a_{1}\right), w+u_{L}\left(a_{1}\right)\right)
$$

then $u_{R}\left(a_{1}\right)+u_{R}\left(a_{2}\right)>0$ and $u_{L}\left(a_{1}\right)+u_{L}\left(a_{2}\right)>0>u_{L}\left(a_{1}\right)$. Thus, the party $L$ will only accept a proposal of alternative $a_{2}$ or a proposal that bundles $a_{1}$ and $a_{2}$. Among these proposals (including the option of making no proposal), party $R$ maximizes their payoff by proposing the $a_{1}$ and $a_{2}$ bundle. Thus, both alternatives will pass.

If $a_{2}$ is bipartisan such that

$$
v_{2} \in\left(\max \left\{-w, w+u_{L}\left(a_{1}\right)\right\}, w\right)
$$

then $u_{L}\left(a_{2}\right)>0>u_{L}\left(a_{1}\right)+u_{L}\left(a_{2}\right)$ and $u_{R}\left(a_{2}\right)>0$. Thus, party $L$ will only accept a proposal of alternative $a_{2}$. Since party $R$ attains a positive payoff from passing $a_{2}$, party $R$ maximizes their payoff by proposing $\left\{a_{2}\right\}$, and $a_{2}$ will pass.

Finally, suppose that $a_{2}$ is divisive such that

$$
v_{2} \notin\left(-w-u_{R}\left(a_{1}\right), w+u_{L}\left(a_{1}\right)\right) \cup\left(\max \left\{-w, w+u_{L}\left(a_{1}\right)\right\}, w\right) .
$$

\footnotetext{
${ }^{31}$ When $L$ is the proposer, the result is similar to that of Lemma 4 (see Footnote 16 ) and the arguments are similar to those found in the proof of Lemma 4 .
} 
We consider three cases. If $v_{2}<-w-u_{R}\left(a_{1}\right)$, then $u_{R}\left(a_{2}\right)<0$ and $u_{R}\left(a_{1}\right)+u_{R}\left(a_{2}\right)<$ 0 . Thus, $R$ maximizes their payoff by passing $a_{1}$ and, failing that, next prefers that no alternative passes. Since party $L$ will always veto a proposal of $a_{1}$, party $R$ will make no proposal, and no alternative will pass. If $v_{2} \in\left(w+u_{L}\left(a_{1}\right), \max \left\{-w, w+u_{L}\left(a_{1}\right)\right\}\right)$, then $u_{R}\left(a_{2}\right)<0$ and $u_{L}\left(a_{1}\right)+u_{L}\left(a_{2}\right)<0 .{ }^{32}$ In this case, party $L$ will only accept a proposal of $a_{2}$; however, since party $R$ receives a negative payoff from passing $a_{2}$, party $R$ maximizes their payoff by making no proposal. Last, if $v_{2}>w$, then $u_{L}\left(a_{2}\right)<0$. In this case, party $L$ receives negative payoff from each alternative (and also from a proposal that bundles both alternatives). Thus, any proposal that party $R$ makes will be vetoed. We conclude that no alternative passes.

Proof of Lemma 4. Suppose $a_{1}$ is available and divisive such that $u_{L}\left(a_{1}\right)>0, u_{R}\left(a_{1}\right)<0$, and assume that party $R$ is the proposer in period $2 .{ }^{33}$

If $a_{2}$ is divisive such that

$$
v_{2} \in\left(\max \left\{w,-u_{R}\left(a_{1}\right)-w\right\}, w+u_{L}\left(a_{1}\right)\right)
$$

then $u_{R}\left(a_{2}\right)>u_{R}\left(a_{1}\right)+u_{R}\left(a_{2}\right)>0$ and $u_{L}\left(a_{1}\right)>u_{L}\left(a_{1}\right)+u_{L}\left(a_{2}\right)>0$. Thus, $R$ maximizes their payoff by passing alternative $a_{2}$ by itself. However, party $L$ receives a negative payoff from $a_{2}$ and, hence, will veto a proposal $\left\{a_{2}\right\}$. Nonetheless, by bundling $a_{1}$ and $a_{2}$, party $R$ and $L$ attain a positive payoff. This is the maximum payoff that $R$ can attain since party $L$ will veto a proposal of $\left\{a_{2}\right\}$, and if $R$ does not make a proposal, then they receive payoff of zero.

If $a_{2}$ is bipartisan, i.e., $v_{2} \in(-w, w)$, then $u_{L}\left(a_{2}\right), u_{R}\left(a_{2}\right)>0$. Thus, $R$ maximizes their payoff by passing alternative $a_{2}$ by itself; this proposal will be accepted by party $L$ since it provides a positive payoff.

\footnotetext{
${ }^{32}$ Note that such a $v_{2}$ exist only if $w+u_{L}\left(a_{1}\right)<-w$.

${ }^{33}$ When $L$ is the proposer, the result is similar to that of Lemma 3 (see Footnote 17) and the arguments are similar to those found in the proof of Lemma 3 .
} 
Finally, suppose $a_{2}$ is divisive such that

$$
v_{2} \notin(-w, w) \cup\left(\max \left\{w,-u_{R}\left(a_{1}\right)-w\right\}, w+u_{L}\left(a_{1}\right)\right) .
$$

We consider three cases. If $v_{2}<-w$, then $u_{R}\left(a_{2}\right)<0$ and $u_{R}\left(a_{1}\right)<0$. Thus, party $R$ will maximize their payoff by passing no alternatives; this is achieved by party $R$ making no proposal. If $v_{2} \in\left(w, \max \left\{w,-u_{R}\left(a_{1}\right)-w\right\}\right)$, then $u_{L}\left(a_{2}\right)<0$ and $u_{R}\left(a_{2}\right)>0>u_{R}\left(a_{1}\right)+$ $u_{R}\left(a_{2}\right)$. Party $R$ will maximize their payoff if $a_{2}$ passes; however, party $L$ will never accept such a proposal. Furthermore, passing both alternatives provides $R$ with negative payoff. Thus, $R$ will optimally make no proposal and no alternative passes. If $v_{2}>w+u_{L}\left(a_{1}\right)$, then $u_{R}\left(a_{2}\right)>0, u_{L}\left(a_{2}\right)<0$, and $u_{L}\left(a_{1}\right)+u_{L}\left(a_{2}\right)<0$. In this case, party $L$ will veto any proposal except for $\left\{a_{1}\right\}$; however, party $R$ prefers to pass no alternative than pass $a_{1}$. As a result, no alternative passes.

Proof of Proposition 1. At the end of period 1, the voter decides whether to elect party $L$ or $R$ for the next period. In each instance, the voter will anticipate the period-2 behavior of each party (as per Lemmas 1 14 ) and elect that party that maximizes their expected payoff from period 2.

Suppose that $a_{1}$ did not pass in period 1 and that $a_{1}$ is bipartisan, i.e., $u_{L}\left(a_{1}\right), u_{R}\left(a_{1}\right)>$ 0 . If the voter elects $R$, then the voter's expected payoff is

$$
\begin{aligned}
& \delta(1-p) \int_{-w}^{w} w d F\left(v_{2}\right) \\
& \quad+\delta p\left(\int_{-w}^{w+u_{L}\left(a_{1}\right)} 2 w d F\left(v_{2}\right)+\int_{w+u_{L}\left(a_{1}\right)}^{+\infty} w d F\left(v_{2}\right)+\int_{-\infty}^{-w} w d F\left(v_{2}\right)\right) .
\end{aligned}
$$


If the voter elects $L$, then the voter's expected payoff is

$$
\begin{aligned}
& \delta(1-p) \int_{-w}^{w} w d F\left(v_{2}\right) \\
& \quad+\delta p\left(\int_{-w-u_{R}\left(a_{1}\right)}^{w} 2 w d F\left(v_{2}\right)+\int_{w}^{+\infty} w d F\left(v_{2}\right)+\int_{-\infty}^{-w-u_{R}\left(a_{1}\right)} w d F\left(v_{2}\right)\right) .
\end{aligned}
$$

The net gain in payoff from electing $R$ is given by the difference between (5) and (6), i.e.,

$$
\begin{aligned}
& \delta p\left(\int_{w}^{w+u_{L}\left(a_{1}\right)} 2 w d F\left(v_{2}\right)-\int_{-w-u_{R}\left(a_{1}\right)}^{-w} 2 w d F\left(v_{2}\right)\right. \\
& \left.\quad-\int_{w}^{w+u_{L}\left(a_{1}\right)} w d F\left(v_{2}\right)+\int_{-w-u_{R}\left(a_{1}\right)}^{-w} w d F\left(v_{2}\right)\right) .
\end{aligned}
$$

Since $F$ is symmetric about zero, (7) simplifies to $\delta p w\left(F\left(w+u_{L}\left(a_{1}\right)\right)-F\left(w+u_{R}\left(a_{1}\right)\right)\right)$, which is positive if and only if $u_{L}\left(a_{1}\right)>u_{R}\left(a_{1}\right)$. It follows that, whenever the period-1 alternative, $a_{1}$, did not pass and is bipartisan, the voter maximizes their expected payoff by electing the party with smallest (positive) payoff.

Suppose $a_{1}$ did not pass in period 1 and that $a_{1}$ is divisive. W.l.o.g. assume that $u_{L}\left(a_{1}\right)<0<u_{R}\left(a_{1}\right)$. If the voter elects $R$, then the voter's expected payoff is

$$
\delta(1-p) \int_{-w}^{w} w d F\left(v_{2}\right)+\delta p\left(\int_{-w-u_{R}\left(a_{1}\right)}^{w+u_{L}\left(a_{1}\right)} 2 w d F\left(v_{2}\right)+\int_{\max \left\{-w, w+u_{L}\left(a_{1}\right)\right\}}^{w} w d F\left(v_{2}\right)\right)
$$

If the voter elects $L$, then the voter's expected payoff is

$$
\delta(1-p) \int_{-w}^{w} w d F\left(v_{2}\right)+\delta p\left(\int_{-w-u_{R}\left(a_{1}\right)}^{\min \left\{-w, w+u_{L}\left(a_{1}\right)\right\}} 2 w d F\left(v_{2}\right)+\int_{-w}^{w} w d F\left(v_{2}\right)\right)
$$

The net gain in payoff from electing $R$ is given by the difference between (8) and (9), i.e.,

$$
\delta p\left(\int_{\min \left\{-w, w+u_{L}\left(a_{1}\right)\right\}}^{w+u_{L}\left(a_{1}\right)} 2 w d F\left(v_{2}\right)-\int_{-w}^{\max \left\{-w, w+u_{L}\left(a_{1}\right)\right\}} w d F\left(v_{2}\right)\right) .
$$

If $-w \geq w+u_{L}\left(a_{1}\right)$ (i.e., $v_{1} \geq 3 w$ ), then the net gain in payoff (10) simplifies to zero and, 
hence, the voter will be indifferent. If $-w<w+u_{L}\left(a_{1}\right)$ (i.e., $\left.v_{1}<3 w\right)$, then the net gain in payoff (10) simplifies to

$$
\delta p\left(\int_{-w}^{w+u_{L}\left(a_{1}\right)} 2 w d F\left(v_{2}\right)-\int_{-w}^{w+u_{L}\left(a_{1}\right)} w d F\left(v_{2}\right)\right)=\delta p\left(\int_{-w}^{w+u_{L}\left(a_{1}\right)} w d F\left(v_{2}\right)\right)
$$

which is positive and, hence, the voter will elect party $R$.

It only remains to show that when $a_{1}$ passes in period 1 the voter is indifferent between each party. This is immediate; when $a_{1}$ is not available in period 2, the outcome from period 2 is independent of the period-2 proposer's identity (Lemma 1 ).

Proof of Proposition 2 Suppose $a_{1}$ is divisive, and w.l.o.g. assume $u_{L}\left(a_{1}\right)<0$ and $u_{R}\left(a_{1}\right)>0$. We will show that party $L$ will always "veto" a period-1 proposal of alternative $a_{1}$ (i.e., if they are the proposer, then they will not make a proposal; if they are the receiver, then they will veto the proposal). To see this, we simply need to show that $L$ receives a lower expected payoff if $a_{1}$ passes than if it does not. If $a_{1}$ passes, $L$ receives an expected payoff

$$
u_{L}\left(a_{1}\right)+\delta \int_{-w}^{w}\left(w-v_{2}\right) d F\left(v_{2}\right)
$$

This follows because if $a_{1}$ passes - regardless of which party is elected as the period2 proposer - only bipartisan period-2 alternatives will pass. If $a_{1}$ does not pass, $L$ 's expected payoff depends on whether $u_{L}\left(a_{1}\right)>-2 w$ or $u_{L}\left(a_{1}\right)<-2 w$; we consider each case below.

Case 1: Suppose that $u_{L}\left(a_{1}\right)>-2 w$. This implies that $-w<w+u_{L}\left(a_{1}\right)$, and party $L$ will anticipate that the voter will elect party $R$ with probability one if $a_{1}$ does not pass 
(Proposition 11). Thus, if $a_{1}$ does not pass, then party $L$ 's expected payoff is

$$
\begin{aligned}
\delta(1- & p) \int_{-w}^{w}\left(w-v_{2}\right) d F\left(v_{2}\right) \\
& +\delta p\left(\int_{-w-u_{R}\left(a_{1}\right)}^{w+u_{L}\left(a_{1}\right)}\left(u_{L}\left(a_{1}\right)+w-v_{2}\right) d F\left(v_{2}\right)+\int_{w+u_{L}\left(a_{1}\right)}^{w}\left(w-v_{2}\right) d F\left(v_{2}\right)\right) .
\end{aligned}
$$

The net gain to party $L$ from $a_{1}$ passing is given by the difference between (11) and (12), i.e.,

$$
\begin{aligned}
& u_{L}\left(a_{1}\right)-\delta p \int_{-w-u_{R}\left(a_{1}\right)}^{-w}\left(u_{L}\left(a_{1}\right)+w-v_{2}\right) d F\left(v_{2}\right)-\delta p \int_{-w}^{w+u_{L}\left(a_{1}\right)} u_{L}\left(a_{1}\right) d F\left(v_{2}\right) \\
& =u_{L}\left(a_{1}\right)\left(1-\delta p \int_{-w}^{w+u_{L}\left(a_{1}\right)} d F\left(v_{2}\right)\right)-\delta p \int_{-w-u_{R}\left(a_{1}\right)}^{-w}\left(u_{L}\left(a_{1}\right)+w-v_{2}\right) d F\left(v_{2}\right),
\end{aligned}
$$

which is negative since $-2 w<u_{L}\left(a_{1}\right)<0$ and $\left(u_{L}\left(a_{1}\right)+w-v_{2}\right)>0$ for all $v_{2} \in(-w-$ $\left.u_{R}\left(a_{1}\right),-w\right)$. Thus, party $L$ has a strict incentive to prevent $a_{1}$ from passing when $0>$ $u_{L}\left(a_{1}\right)>-2 w$, and $a_{1}$ will not pass.

Case 2: Suppose that $u_{L}\left(a_{1}\right)<-2 w$. This implies that $-w>w+u_{L}\left(a_{1}\right)$, and party $L$ will anticipate that the voter is indifferent between electing each party if $a_{1}$ does not pass (Proposition 1). Similarly, party $L$ and $R$ are indifferent between which party is elected, since the period-2 outcome is independent of the period-2 proposer's identity. Thus, if $a_{1}$ does not pass, then party $L$ 's expected payoff

$$
\begin{aligned}
\delta(1- & p) \int_{-w}^{w}\left(w-v_{2}\right) d F\left(v_{2}\right) \\
& +\delta p\left(\int_{-w-u_{R}\left(a_{1}\right)}^{w+u_{L}\left(a_{1}\right)}\left(u_{L}\left(a_{1}\right)+w-v_{2}\right) d F\left(v_{2}\right)+\int_{-w}^{w}\left(w-v_{2}\right) d F\left(v_{2}\right)\right) .
\end{aligned}
$$

The net gain to party $L$ from $a_{1}$ passing is given by the difference between (11) and (13), 
i.e.,

$$
u_{L}\left(a_{1}\right)-\delta p\left(\int_{-w-u_{R}\left(a_{1}\right)}^{w+u_{L}\left(a_{1}\right)}\left(u_{L}\left(a_{1}\right)+w-v_{2}\right) d F\left(v_{2}\right)\right)
$$

which is negative since $u_{L}\left(a_{1}\right)<0$ and

$$
\left(u_{L}\left(a_{1}\right)+w-v_{2}\right)>0 \quad \text { for all } v_{2} \in\left(-w-u_{R}\left(a_{1}\right), w+u_{L}\left(a_{1}\right)\right) .
$$

Thus, party $L$ has a strict incentive to prevent $a_{1}$ from passing when $-2 w>u_{L}\left(a_{1}\right)$, and $a_{1}$ will not pass.

Proof of Lemma 5. Suppose $a_{1}$ is bipartisan, i.e., $u_{L}\left(a_{1}\right), u_{R}\left(a_{1}\right)>0$, and w.l.o.g. assume $0<u_{R}\left(a_{1}\right)<u_{L}\left(a_{1}\right)$. We will show that $L$ always prefers that $a_{1}$ passes and, hence, will never veto or delay a proposal $\left\{a_{1}\right\}$. To see this, note that if $a_{1}$ passes, then party $L$ receives expected payoff

$$
u_{L}\left(a_{1}\right)+\delta \int_{-w}^{w}\left(w-v_{2}\right) d F\left(v_{2}\right)
$$

On the other hand, if $a_{1}$ does not pass, then $L$ anticipates that $R$ will be elected with probability one and, hence, party $L$ 's expected payoff is

$$
\begin{aligned}
\delta(1-p) \int_{-w}^{w}\left(w-v_{2}\right) d F\left(v_{2}\right)+\delta p\left(\int_{-w}^{w+u_{L}\left(a_{1}\right)}\left(u_{L}\left(a_{1}\right)+w-v_{2}\right) d F\left(v_{2}\right)\right. \\
\left.+\int_{w+u_{L}\left(a_{1}\right)}^{+\infty} u_{L}\left(a_{1}\right) d F\left(v_{2}\right)+\int_{-\infty}^{-w} u_{L}\left(a_{1}\right) d F\left(v_{2}\right)\right) .
\end{aligned}
$$

The net gain to party $L$ when $a_{1}$ passes is given by the difference between (14) and (15), 
i.e.,

$$
\begin{aligned}
& u_{L}\left(a_{1}\right)+\delta \int_{-w}^{w}\left(w-v_{2}\right) d F\left(v_{2}\right)-\delta(1-p) \int_{-w}^{w}\left(w-v_{2}\right) d F\left(v_{2}\right) \\
& -\delta p\left(\int_{-w}^{w+u_{L}\left(a_{1}\right)}\left(u_{L}\left(a_{1}\right)+w-v_{2}\right) d F\left(v_{2}\right)+\int_{w+u_{L}\left(a_{1}\right)}^{+\infty} u_{L}\left(a_{1}\right) d F\left(v_{2}\right)+\int_{-\infty}^{-w} u_{L}\left(a_{1}\right) d F\left(v_{2}\right)\right) \\
= & u_{L}\left(a_{1}\right)(1-\delta p)-\delta p\left(\int_{-w}^{w+u_{L}\left(a_{1}\right)}\left(w-v_{2}\right) d F\left(v_{2}\right)-\int_{-w}^{w}\left(w-v_{2}\right) d F\left(v_{2}\right)\right) \\
= & u_{L}\left(a_{1}\right)(1-\delta p)-\delta p \int_{w}^{w+u_{L}\left(a_{1}\right)}\left(w-v_{2}\right) d F\left(v_{2}\right),
\end{aligned}
$$

which is positive since $w-v_{2}<0$ for all $v_{2}>w$. Thus, party $L$ has a strict incentive in period 1 to assist $a_{1}$ in passing and, hence, will never veto or delay a proposal $\left\{a_{1}\right\}$.

Proof of Proposition 3, Suppose $a_{1}$ is bipartisan, i.e., $u_{L}\left(a_{1}\right), u_{R}\left(a_{1}\right)>0$, and w.l.o.g. assume $0<u_{R}\left(a_{1}\right)<u_{L}\left(a_{1}\right)$. Given that party $L$ will never veto or delay $a_{1}$ (Lemma 5), we wish to characterize the conditions under which party $R$ will choose to veto or delay a period-1 proposal $\left\{a_{1}\right\}$.

If $a_{1}$ passes, then party $R$ receives expected payoff

$$
u_{R}\left(a_{1}\right)+\delta \int_{-w}^{w}\left(w+v_{2}\right) d F\left(v_{2}\right)
$$

If $a_{1}$ does not pass, then $R$ anticipates that they will be elected with probability one and, hence, has expected payoff

$$
\begin{array}{r}
\delta(1-p) \int_{-w}^{w}\left(w+v_{2}\right) d F\left(v_{2}\right)+\delta p\left(\int_{-w}^{w+u_{L}\left(a_{1}\right)}\left(u_{R}\left(a_{1}\right)+w+v_{2}\right) d F\left(v_{2}\right)\right. \\
\left.+\int_{w+u_{L}\left(a_{1}\right)}^{+\infty} u_{R}\left(a_{1}\right) d F\left(v_{2}\right)+\int_{-\infty}^{-w} u_{R}\left(a_{1}\right) d F\left(v_{2}\right)\right) .
\end{array}
$$

Taking the difference between (16) and (17) and simplifying, shows that Party $R$ receives 
non-negative payoff from passing $a_{1}$ if and only if

$$
u_{R}\left(a_{1}\right)(1-\delta p)-\delta p \int_{w}^{w+u_{L}\left(a_{1}\right)}\left(w+v_{2}\right) d F\left(v_{2}\right) \geq 0
$$

By defining (18) as $\Phi_{R}$, we attain the condition for party $R$ in the proposition statement. When the payoffs are such that $0<u_{L}\left(a_{1}\right)<u_{R}\left(a_{1}\right)$, party $L$ 's condition (as stated in the proposition) can be derived similarly.

Proof of Proposition 4. Consider the final period and suppose $R$ is the period-2 proposer. Party $R$ will make a proposal (or perhaps make no proposal) that maximizes their payoff among the set of available proposals that provide party $L$ with a non-negative payoff.

If $a_{1}$ is not available, then $R$ decides whether to propose $\left\{a_{2}\right\}$. Party $R$ will want to pass $a_{2}$ whenever it provides a positive payoff to party $R$ (i.e., if $v_{2}>-w$ ), but $L$ will accept $a_{2}$ if and only if $v_{2}<w$. It follows that alternative $a_{2}$ will pass if and only if $v_{2} \in(-w, w)$, i.e., $a_{2}$ is bipartisan.

If $a_{1}$ is available, then $R$ decides whether to propose $a_{1}$ and/or $a_{2}$. Since there is no policy bundling, each party has veto power to prevent each alternative passing. Thus, $a_{1}$ passes if and only if it provides positive payoff to each party (i.e., if $a_{1}$ is bipartisan) and, similarly, $a_{2}$ passes if and only if it provides positive payoff to each party (i.e., if $a_{2}$ is bipartisan).

We now turn to the voter's decision. As can be seen above, the policy outcome for period 2 is independent of the proposer. This means that the voter (and also the parties) are indifferent between each party being elected as the period-2 proposer.

Finally, we consider period 1. Suppose that $a_{1}$ is divisive, and w.l.o.g. assume that party $R$ is the party that receives a negative payoff. If $a_{1}$ does not pass, then $R$ receive expected payoff

$$
\delta \int_{-w}^{w}\left(w+v_{2}\right), d F\left(v_{2}\right)
$$


However, if $a_{1}$ does pass, then $R$ receive expected payoff

$$
u_{R}\left(a_{1}\right)+\delta \int_{-w}^{w}\left(w+v_{2}\right), d F\left(v_{2}\right)
$$

Since $u_{R}\left(a_{1}\right)<0$, party $R$ prefers that $a_{1}$ does not pass and, thus, $a_{1}$ will not pass. Now suppose that $a_{1}$ is bipartisan. If $a_{1}$ does not pass, then $R$ and $L$ receive expected payoffs

$$
\delta p u_{R}\left(a_{1}\right)+\delta \int_{-w}^{w}\left(w+v_{2}\right), d F\left(v_{2}\right) \quad \text { and } \quad \delta p u_{L}\left(a_{1}\right)+\delta \int_{-w}^{w}\left(w-v_{2}\right), d F\left(v_{2}\right),
$$

respectively. However, if $a_{1}$ does pass, then $R$ and $L$ receive expected payoffs of

$$
u_{R}\left(a_{1}\right)+\delta \int_{-w}^{w}\left(w+v_{2}\right) d F\left(v_{2}\right) \quad \text { and } \quad u_{L}\left(a_{1}\right)+\delta \int_{-w}^{w}\left(w-v_{2}\right), d F\left(v_{2}\right),
$$

respectively. It is immediate that both parties prefer to pass $a_{1}$; thus $a_{1}$ will pass in period 1 whenever it is bipartisan. This completes the proof.

Proof of Proposition 5. First, as a benchmark, we consider the probability of each form of gridlock under the modified model without policy bundling. In this setting, it is immediate from Proposition 4 that preference-based gridlock occurs with probability

$$
\int_{-\infty}^{-w} d F\left(v_{2}\right)+\int_{w}^{+\infty} d F\left(v_{2}\right)=F(-w)+1-F(w)=2[1-F(w)]
$$

in each period, and leverage-based gridlock occurs with probability zero. It follows that the total probability of gridlock in period 1 is given by (19).

We now consider the main model with policy bundling. We begin with period 1 . Preference-based gridlock occurs whenever the period- 1 alternative is divisive (i.e., $v_{1} \notin$ $(-w, w))$; thus, preference-based gridlock occurs with probability

$$
2[1-F(w)]
$$


as per the no-policy-bundling model. Leverage-based gridlock occurs whenever the period-1 alternative is bipartisan and $\Phi_{j}$ (as defined in Proposition 3) is negative. Thus, leverage-based gridlock occurs with probability

$$
\int_{v_{1} \in(0, w): \Phi_{L}\left(v_{1}\right)<0} d F\left(v_{2}\right)+\int_{v_{1} \in(-w, 0): \Phi_{R}\left(v_{1}\right)<0} d F\left(v_{2}\right)=2 \int_{v_{1} \in(0, w): \Phi_{L}\left(v_{1}\right)<0} d F\left(v_{2}\right),
$$

which is positive since $\Phi_{L}\left(v_{1}\right)$ is negative for $v_{1}$ sufficiently close to $w \cdot{ }^{34}$ It follows that the total probability of gridlock in period 1 is given by the sum of $(20)$ and $(21)$, which is strictly greater than the probability of period-1 gridlock without policy bundling.

We now consider period 2. Using a symmetry argument, preference-based gridlock occurs with probability

$$
\begin{aligned}
& 2 \int_{v_{1} \in(0, w): \Phi_{L}\left(v_{1}\right)>0} 2[1-F(w)] d F\left(v_{1}\right) \\
& \quad+2 \int_{v_{1} \in(0, w): \Phi_{L}\left(v_{1}\right)<0}\left(1-\left[F(w)-F\left(-w-u_{R}\left(a_{1}\right)\right)\right]\right) d F\left(v_{1}\right) \\
& \quad+2 \int_{w}^{3 w}\left(1-\left[F(w)-F\left(-w-u_{R}\left(a_{1}\right)\right)\right]\right) d F\left(v_{1}\right) \\
& \quad+2 \int_{3 w}^{\infty}\left(1-[F(w)-F(-w)]-\left[F\left(w+u_{L}\left(a_{1}\right)-F\left(-w-u_{R}\left(a_{1}\right)\right]\right) d F\left(v_{1}\right) .\right.\right.
\end{aligned}
$$

Since each integrand is (weakly) less than $2[1-F(w)]=1-[F(w)-F(-w)]$ and the last three integrands are strictly less, the probability (22) is strictly less than the probability of preference-based gridlock without bundling in period 2 given by (19). Furthermore, notice that - since period 2 is the final period - leverage-based gridlock occurs with probability zero. It follows that the total probability of gridlock in period 2 is given by (22), which is strictly less than the probability of period-2 gridlcok without policy bundling.

Proof of Proposition 6. Suppose the period-1 alternative, $a_{1}$, is bipartisan, and w.l.o.g.

\footnotetext{
${ }^{34}$ Note that, for any fixed set of parameters, the set of $v_{1} \in(-w, 0): \Phi_{R}\left(v_{1}\right)=0$ has zero measure; in particular, there is either no $v_{1} \in(-w, 0)$ or there is a unique $v_{1}$ such that $\Phi_{R}\left(v_{1}\right)=0$. This follows because the left hand side of $(18)$ is strictly increasing for $v_{1}$ in $(-w, 0)$. Similarly, the set $\left\{v_{1} \in(0, w): \Phi_{L}\left(v_{1}\right)=0\right\}$ has zero measure.
} 
assume that $0<u_{R}\left(a_{1}\right)<u_{L}\left(a_{1}\right)$, i.e., $v_{1} \in(-w, 0)$. Leverage-based gridlock will occur whenever

$$
\Phi_{R}=(1-\delta p) u_{R}\left(a_{1}\right)-\delta p \int_{w}^{w+u_{L}\left(a_{1}\right)}\left(w+v_{2}\right) d F\left(v_{2}\right)<0 .
$$

We wish to prove that a marginal decrease in $v_{1}$ increases the set of parameters (w.r.t. the set-inclusion ordering) that induce leverage-based gridlock. By applying Leibniz's rule for differentiation under the integral sign, we attain

$$
\frac{\partial \Phi_{R}\left(v_{1}\right)}{\partial v_{1}}=(1-\delta p)-\delta p\left(3 w-v_{1}\right)(-1)
$$

which is positive for $\left|v_{1}\right|<w$. We conclude that a marginal decrease in $v_{1}$ leads to a decrease in $\Phi_{R}\left(v_{1}\right)$ for all parameters values and, hence, the set of parameters that induce leverage-based gridlock increases.

Finally, we note that if the decrease in the partisan component is sufficiently large such that $v_{1}<-w$, then the alternative, $a_{1}$, will become divisive. In this case, the alternative never passes.

Proof of Proposition 7, First note that if the period-1 alternative is divisive $\left(\left|v_{1}\right|>\right.$ $w)$, then leverage-based gridlock never occurs and preference-based gridlock always occurs. Hence, the comparative statics in the proposition statement are (trivially) true for preference-based gridlock.

Now consider the case where the alternative is bipartisan $\left(\left|v_{1}\right|<w\right)$, and w.l.o.g. assume $0<u_{R}\left(a_{1}\right)<u_{L}\left(a_{1}\right)$. Leverage-based gridlock will occur whenever

$$
\Phi_{R}=(1-\delta p) u_{R}\left(a_{1}\right)-\delta p \int_{w}^{w+u_{L}\left(a_{1}\right)}\left(w+v_{2}\right) d F\left(v_{2}\right)<0
$$

We wish to prove that a marginal decrease in $p$ or $\delta$ increases the set of parameters (w.r.t. the set-inclusion ordering) that induce leverage-based gridlock. By differentiating $\Phi_{R}$ as 
a function of $\delta$ and $p$, we attain

$$
\begin{aligned}
& \frac{\partial \Phi_{R}\left(v_{1}\right)}{\partial \delta}=-p u_{R}\left(a_{1}\right)-p \int_{w}^{w+u_{L}\left(a_{1}\right)}\left(w+v_{2}\right) d F\left(v_{2}\right) \quad \text { and } \\
& \frac{\partial \Phi_{R}\left(v_{1}\right)}{\partial p}=-\delta u_{R}\left(a_{1}\right)-\delta \int_{w}^{w+u_{L}\left(a_{1}\right)}\left(w+v_{2}\right) d F\left(v_{2}\right)
\end{aligned}
$$

It is immediate that both the above derivatives are negative. We conclude that a marginal increase in $\delta$ or $p$ leads to a decrease in $\Phi_{R}\left(v_{1}\right)$ for all parameters values and, hence, the set of parameters that induce leverage-based gridlock increases.

Proof of Proposition 8. First, we prove that polarization increases the frequency of preference-based gridlock in period 1. Let $F$ be the (symmetric) distribution of each period's partisan component. In period 1, the probability of preference-based gridlock is simply the probability that the period-1 alternative is divisive. Let $\operatorname{Pr}_{F}\left[\left|v_{t}\right|<x\right]$ denote the probability that $a_{t}$ has partisan component with absolute value less than $x$.

Now let $G$ be a new (symmetric) distribution that increases polarization. By definition, it must be that the distribution of the absolute value of $v_{t}$ under $G$ first-order stochastically dominates the absolute value of $v_{t}$ under $F$, i.e., $\operatorname{Pr}_{G}\left[\left|v_{t}\right|<x\right] \leq \operatorname{Pr}_{F}\left[\left|v_{t}\right|<x\right]$ for all $x$, with strict inequality holding for some $x$. This immediately implies that an alternative is at least as likely to be divisive under the distribution $G$, compared to $F$, since

$$
\underset{G}{\operatorname{Pr}}\left[\left|v_{t}\right|<w\right] \leq \underset{F}{\operatorname{Pr}}\left[\left|v_{t}\right|<w\right]
$$

Thus, preference-based gridlock is increasing with polarization.

Second, we prove that the frequency of leverage-based gridlock and period- 1 gridlock can be non-monotonic in the level of polarization. We prove both results with a single example.

For this proof, we consider three different distributions of $v_{t}$ which we denote by $F, G$ and $H$. These distributions have density functions $f, g, h$ defined as follows; an intuitive 
description of each distribution is included after the formal definitions.

$$
\begin{aligned}
& f(v)= \begin{cases}\frac{1}{2 w} \quad \text { if } v \in[-w, w], \\
0 \quad \text { otherwise; }\end{cases} \\
& g(v)= \begin{cases}\frac{1}{2 w} \eta & \text { if } v \in[-w, w], \\
\frac{1}{2 \varepsilon}(1-\eta) & \text { if } v \in[-w-\varepsilon,-w] \cup[w, w+\varepsilon], \\
0 & \text { otherwise; }\end{cases} \\
& h(v)= \begin{cases}\frac{1}{2 w} \eta & \text { if } v \in[-w, w], \\
\frac{1}{2 \varepsilon}(1-\eta) & \text { if } v \in[-\xi-w-\varepsilon,-\xi-w] \cup[\xi+w, \xi+w+\varepsilon], \\
0 & \text { otherwise; }\end{cases}
\end{aligned}
$$

where $\eta \in(0,1), 0<\varepsilon<2 w<\xi$. That is, $F$ has the partisan component uniformly distributed between $-w$ and $w$; this means that alternatives are always bipartisan. The distribution $G$ can be viewed as the combination of two distributions. A portion of mass, $\eta \in(0,1)$, is uniformly distributed between $-w$ and $w$, and the remaining portion of mass is uniformly distributed in the discontiguous set $[-w-\varepsilon,-w]$ and $[w, w+\varepsilon]$ for some small $\varepsilon>0$. Lastly, the distribution $H$ is similar to the distribution $G$ but the $(1-\eta)$ portion of mass is distributed in a discontiguous set that is further away from the center-of-mass $v=0$.

It is immediate that each distribution has mean zero, polarization is higher under $H$ than under $G$, and polarization is higher under $G$ than under $F .{ }^{35}$

We now proceed with showing that the probability of leverage-based gridlock is nonmonotonic. Under distribution $F$, the probability of leverage-based gridlock is zero; this follows since $\Phi_{j}$ (from Proposition 3) is non-negative. Under distribution $G$, the probability of leverage-based gridlock is positive. To see this, note that when $v_{1} \in(-w, 0)$

\footnotetext{
${ }^{35} \mathrm{By}$ transitivity, this implies that $H$ is also a mean-preserving spread of $F$.
} 
leverage-based gridlock occurs whenever

$$
\Phi_{R}=(1-\delta p) u_{R}\left(a_{1}\right)-\delta p \int_{w}^{w+u_{L}\left(a_{1}\right)}\left(w+v_{2}\right) d G\left(v_{2}\right)<0
$$

Now suppose that $v_{1} \in[-w,-w+\mu]$ for $\mu>0$, which occurs with probability $\mu / 2$, the function $\Phi_{R}$ can be bounded as follows

$$
\begin{array}{rlr}
\Phi_{R} & =(1-\delta p) u_{R}\left(a_{1}\right)-\delta p \int_{w}^{w+u_{L}\left(a_{1}\right)}\left(w+v_{2}\right) d G\left(v_{2}\right) \\
& <(1-\delta p) \mu-\delta p \int_{w}^{3 w-\mu}\left(w+v_{2}\right) d G\left(v_{2}\right) & \\
& <(1-\delta p) \mu-\delta p 2 w[G(3 w-\mu)-G(w)] & \text { as } \mu \rightarrow 0 .
\end{array}
$$

It follows that for sufficiently small $\mu>0$ when $v_{1} \in[-w,-w+\mu]$ leverage-based gridlock will occur. Let $Q$ denote this positive probability.

Finally, we consider the distribution $H$. We argue that leverage-based gridlock will never occur. To see this, note that when $v_{1} \in(-w, 0)$ leverage-based gridlock occurs whenever

$$
\Phi_{R}=(1-\delta p) u_{R}\left(a_{1}\right)-\delta p \int_{w}^{w+u_{L}\left(a_{1}\right)}\left(w+v_{2}\right) d H\left(v_{2}\right)<0 .
$$

However, under the distribution $H$ we have that for $v_{1} \in[-w, 0]$

$$
\Phi_{R} \geq(1-\delta p) u_{R}\left(a_{1}\right)-\delta p \int_{w}^{3 w}\left(w+v_{2}\right) d H\left(v_{2}\right)=(1-\delta p) u_{R}\left(a_{1}\right)
$$

which is non-negative. Thus, leverage-based gridlock never occurs under the distribution $H$.

To summarize, the probability of leverage-based gridlock is 0 under $F$, occurs with probability at least $Q>0$ under $H$ and occurs with probability zero under $G$.

To complete the proof, we note that the probability of total period-1 gridlock (combin- 
ing both leverage- and preference-based gridlock) is non-monotonic. The probability of any gridlock is 0 under $F$, occurs with probability at least $1-\eta+Q$ under $H$ and occurs with probability $1-\eta$ under $G$.

Proof of Proposition 9. We first consider the condition under which the voter prefers that a bipartisan period 1 alternative $a_{1}$ (i.e., $\left|v_{1}\right|<w$ ) does not pass. If $a_{1}$ passes, the voter's expected payoff is

$$
w+\delta \int_{-w}^{w} w d F\left(v_{2}\right)=w+\delta w[F(w)-F(-w)]
$$

If $a_{1}$ does not pass, the voter's expected payoff is

$$
\begin{aligned}
& \delta(1-p) \int_{-w}^{w} w d F\left(v_{2}\right)+\delta p w+\delta p \begin{cases}\int_{-w}^{w+u_{L}\left(a_{1}\right)} w d F\left(v_{2}\right) & \text { if } v_{1} \in(-w, 0) \\
\int_{-w-u_{R}\left(a_{1}\right)}^{w} w d F\left(v_{2}\right) & \text { if } v_{1} \in(0, w) .\end{cases} \\
& =\delta(1-p) w[F(w)-F(-w)]+\delta p w+\delta p w \begin{cases}F\left(2 w-v_{1}\right)-F(-w) & \text { if } v_{1} \in(-w, 0), \\
F(w)-F\left(-2 w-v_{1}\right) & \text { if } v_{1} \in(0, w) .\end{cases} \\
& =\delta(1-p) w[F(w)-F(-w)]+\delta p w+\delta p w\left(F\left(2 w+\left|v_{1}\right|\right)-F(-w)\right)
\end{aligned}
$$

The net benefit of passing $a_{1}$ is given by the difference between (23) and (24), i.e.,

$$
\begin{aligned}
& \Phi_{V}:=w+\delta w[F(w)-F(-w)]-\delta(1-p) w[F(w)-F(-w)]-\delta p w \\
& \quad-\delta p w\left(F\left(2 w+\left|v_{1}\right|\right)-F(-w)\right) \\
&=w(1-\delta p)-p \delta w\left(F\left(2 w+\left|v_{1}\right|\right)-F(w)\right)
\end{aligned}
$$

Since $a_{1}$ is bipartisan, we have that $\left|v_{1}\right|<w$, and the net benefit (25) has lower bound

$$
w(1-\delta p)-p \delta w(F(3 w)-F(w))
$$


and upper bound

$$
w(1-\delta p)-p \delta w(F(2 w)-F(w))
$$

Thus, if

$$
w(1-\delta p)-p \delta w(F(3 w)-F(w))>0 \Longleftrightarrow F(3 w)-F(w)<1 /(\delta p)-1,
$$

then for all $\left|v_{1}\right|<w$ the voter attains a net benefit from passing $a_{1}$ and, hence, leveragebased gridlock is always inefficient. Alternatively, if

$$
w(1-\delta p)-p \delta w(F(2 w)-F(w))<0 \Longleftrightarrow F(2 w)-F(w)>1 /(\delta p)-1,
$$

then for all $\left|v_{1}\right|<w$ the voter attains a net loss from passing $a_{1}$ and, hence, leveragebased gridlock is always efficient. Note that these conditions are tight: if either does not hold, then with some positive probability $v_{1}$ will be such that leverage-based gridlock is efficient and with some positive probability $v_{1}$ will be such that leverage-based gridlock is inefficient.

Proof of Proposition 10. First, we note that the proposition is trivially true for preferencebased gridlock. This follows because - regardless of whether gridlock is efficient preference-based gridlock occurs if and only if $a_{1}$ is divisive.

Second, we consider leverage-based gridlock, which arises when the period-1 alternative is bipartisan. We prove the result via an accounting argument. Recall that if $a_{1}$ is bipartisan $\left(\left|v_{1}\right|<w\right)$, the party with smallest payoff induces leverage-based gridlock if and only if their net payoff from passing the alternative is negative, i.e., $\Phi_{j}<0$ (where $\Phi_{j}$ is defined as in Proposition 3). Now, notice that gridlock is efficient whenever the voter attains a negative net payoff from passing $a_{1}$; this corresponds to $\Phi_{V}<0$ where $\Phi_{V}$ is defined in (25) within the proof of Proposition 9. However, the voter's payoff in any 
instance is, by construction, the sum of the two parties' payoffs. Thus,

$$
\Phi_{V}=\Phi_{L}+\Phi_{R}
$$

Furthermore, note that, with exception of events that occur with probability zero, in any instance at least one of $\Phi_{L}$ or $\Phi_{R}$ is positive, i.e., when $v_{1} \in(-w, 0)$ we have $\Phi_{L}>0$ and when $v_{1} \in(0, w)$ we have $\Phi_{R}>0$. It now follows that if gridlock is efficient, then $\Phi_{V}<0$, and so

$$
\Phi_{L}+\Phi_{R}<0
$$

But since either $\Phi_{L}$ or $\Phi_{R}$ must be positive, we conclude that either $\Phi_{R}$ or $\Phi_{L}$ must be negative and, hence, gridlock will occur in equilibrium.

Finally, it is straightforward to see that inefficient gridlock can still arise in equilibrium. For example, suppose that $v_{1} \in(-w, 0), 0<F(3 w)-F(w)<1 /(\delta p)-1$ so that leverage-based gridlock is always inefficient for the voter (as per Proposition 9). In this case, we have that leverage-based gridlock occurs whenever $\Phi_{R}<0$, where

$$
\begin{aligned}
\Phi_{R} & =u_{R}\left(a_{1}\right)(1-\delta p)-\delta p \int_{w}^{w+u_{L}\left(a_{1}\right)}\left(w+v_{2}\right) d F\left(v_{2}\right) \\
& \leq\left(w+v_{1}\right)(1-\delta p)-\delta p 2 w[F(2 w)-F(w)] .
\end{aligned}
$$

For $v_{1}$ sufficiently close to $-w$, the above upper bound on $\Phi_{R}$ is negative and, hence, leverage-based gridlock will be induced in equilibrium — despite it being inefficient.

Proof of Proposition 11. We begin with the case where the period-1 alternative is bipartisan $\left(\left|v_{1}\right|<w\right)$. In this case, it suffices to show that the voter can choose a strategy that ensures $a_{1}$ passes. ${ }^{36}$ In particular, we consider the following blame-game strategy: if exactly one party vetoes $a_{1}$ (i.e., by proposing no proposal or by rejecting a proposal), then

\footnotetext{
${ }^{36}$ In which case, the voter will implement this strategy whenever gridlock is inefficient but following the sequentially rational strategy leads to gridlock. On the other hand, when gridlock is efficient, the voter can follow the sequentially rational strategy since, in equilibrium, gridlock will arise (Proposition 10 )
} 
the voter elects the other party as the period-2 proposer. If both or neither party vetoes $a_{1}$, then the voter elects party $R$.

When the voter follows the above strategy, there is a unique equilibrium and, in this equilibrium, neither party vetoes $a_{1}$ and $a_{1}$ passes. We begin by making two observations.

Observation 1: Each party strictly prefers that $a_{1}$ pass than for $a_{1}$ to not pass and for the other party to be elected for period 2 .

Observation 2: If $a_{1}$ does not pass, then each party strictly prefers to be elected for period 2 .

First, for sake of a contradiction, suppose that party $R$ plays a non-degenerate mixed strategy. In this case, party $L$ has a strict incentive not to veto $a_{1}$. Since, if $L$ vetoes $a_{1}$, then $a_{1}$ never passes and party $R$ is always elected for period 2 . However, if $L$ does not veto $a_{1}$, then two cases emerge. Either $a_{1}$ passes, or $a_{1}$ does not pass (due to $R$ vetoing) and then party $L$ is elected. Given observation 1 , party $L$ will never veto. But then this leads to contradiction. If party $L$ never vetoes, then party $R$ will strictly prefer to not veto $a_{1}$ and, hence, must be following a degenerate mixed strategy. This follows because whenever party $R$ vetoes $a_{1}, a_{1}$ does not pass and the voter elects party $L$ (since party $L$ did not veto) which leaves party $R$ worse off than if they were not to veto $a_{1}$ (as per observation 1).

It remains to consider the two possible degenerate strategies that $R$ could follow. If $R$ always vetoes $a_{1}$, then party $L$ must not veto. This follows because party $L$ 's choice of whether to veto has no effect on the period-1 outcome, but if party $L$ does not veto then they will be elected for period 2. By observation 2, party $L$ will not veto. But we now have a contradiction: if party $L$ does not veto, then it is not a best response for $R$ to veto $a_{1}$ (observation 1 ). Now suppose that $R$ never vetoes. Party $L$ has a strict incentive also not to veto (as per observation 1): if they were to veto, then $a_{1}$ would not pass and party $R$ would be elected. Furthermore, party $R$ not vetoing is a best a response to party $L$ never vetoing. We conclude that the unique equilibrium is for neither party to veto and, hence, 
the voter can ensure that $a_{1}$ will pass.

Lastly, we consider the case where the period-1 alternative is divisive $\left(\left|v_{1}\right|>w\right)$. We argue that, for any voting strategy, the voter - even with commitment power - cannot never generate an equilibrium whereby no party vetoes $a_{1}$. We consider an arbitrary strategy for the voter. Let $r\left(x_{L}, x_{R}\right) \in[0,1]$ be the probability that the voter elects party $R$ for period 2 as a function of each party's action $x_{L}, x_{R} \in\{0,1\}$ where $x_{L}=1$ if and only if party $L$ vetoes $a_{1}$ (and similar for party $R$ ).

W.l.o.g. assume that the period- 1 alternative is divisive such that $v_{1}<-w$, so that party $R$ receives a negative payoff from $a_{1}$. We will show that for any voter strategy $r$, party $R$ strictly prefers to veto $a_{1}$ whenever they are pivotal in deciding whether $a_{1}$ passes. Suppose $R$ is pivotal (i.e., $x_{L}=0$ ), party $R$ will allow $a_{1}$ to pass when the following expression (the net gain from passing $a_{1}$ ) is positive:

$$
\begin{aligned}
& u_{R}\left(a_{1}\right)+\delta \int_{-w}^{w}\left(w+v_{2}\right) d F\left(v_{2}\right)-\delta(1-p) \int_{-w}^{w}\left(w+v_{2}\right) d F\left(v_{2}\right) \\
& -\delta p\left(r(0,1)\left[\int_{\max \left\{w,-u_{R}\left(a_{1}\right)-w\right\}}^{w+u_{L}\left(a_{1}\right)}\left(u_{R}\left(a_{1}\right)+w+v_{2}\right) d F\left(v_{2}\right)+\int_{-w}^{w}\left(w+v_{2}\right) d F\left(v_{2}\right)\right]\right. \\
& \left.+(1-r(0,1))\left[\int_{-w-u_{R}\left(a_{1}\right)}^{w+u_{L}\left(a_{1}\right)}\left(u_{R}\left(a_{1}\right)+w+v_{2}\right) d F\left(v_{2}\right)+\int_{-w}^{\min \left\{w,-w-u_{R}\left(a_{1}\right)\right\}}\left(w+v_{2}\right) d F\left(v_{2}\right)\right]\right) .
\end{aligned}
$$

Suppose that $v_{1}<-3 w$, then

$$
\min \left\{w,-w-u_{R}\left(a_{1}\right)\right\}=w \quad \text { and } \quad \max \left\{w,-w-u_{R}\left(a_{1}\right)\right\}=-w-u_{R}\left(a_{1}\right) .
$$


This leads (28) to simplify to

$$
\begin{aligned}
& u_{R}\left(a_{1}\right)+\delta \int_{-w}^{w}\left(w+v_{2}\right) d F\left(v_{2}\right)-\delta(1-p) \int_{-w}^{w}\left(w+v_{2}\right) d F\left(v_{2}\right) \\
& \quad-\delta p\left(r(0,1)\left[\int_{-w-u_{R}\left(a_{1}\right)}^{w+u_{L}\left(a_{1}\right)}\left(u_{R}\left(a_{1}\right)+w+v_{2}\right) d F\left(v_{2}\right)+\int_{-w}^{w}\left(w+v_{2}\right) d F\left(v_{2}\right)\right]\right. \\
& \left.\quad+(1-r(0,1))\left[\int_{-w-u_{R}\left(a_{1}\right)}^{w+u_{L}\left(a_{1}\right)}\left(u_{R}\left(a_{1}\right)+w+v_{2}\right) d F\left(v_{2}\right)+\int_{-w}^{w}\left(w+v_{2}\right) d F\left(v_{2}\right)\right]\right) \\
& =u_{R}\left(a_{1}\right)-\delta p\left(\left[\int_{-w-u_{R}\left(a_{1}\right)}^{w+u_{L}\left(a_{1}\right)}\left(u_{R}\left(a_{1}\right)+w+v_{2}\right) d F\left(v_{2}\right)\right]\right),
\end{aligned}
$$

which is negative and independent of the voter's strategy, $r$. Thus, party $R$ will veto $a_{1}$.

Now suppose $v_{1} \in(-3 w,-w)$. In this case,

$$
\min \left\{w,-w-u_{R}\left(a_{1}\right)\right\}=-w-u_{R}\left(a_{1}\right) \quad \text { and } \quad \max \left\{w,-w-u_{R}\left(a_{1}\right)\right\}=w,
$$

and (28) simplifies to

$$
\begin{aligned}
& u_{R}\left(a_{1}\right)+\delta \int_{-w}^{w}\left(w+v_{2}\right) d F\left(v_{2}\right)-\delta(1-p) \int_{-w}^{w}\left(w+v_{2}\right) d F\left(v_{2}\right) \\
& \quad-\delta p\left(r(0,1)\left[\int_{w}^{w+u_{L}\left(a_{1}\right)}\left(u_{R}\left(a_{1}\right)+w+v_{2}\right) d F\left(v_{2}\right)+\int_{-w}^{w}\left(w+v_{2}\right) d F\left(v_{2}\right)\right]\right. \\
& \left.\quad+(1-r(0,1))\left[\int_{-w-u_{R}\left(a_{1}\right)}^{w+u_{L}\left(a_{1}\right)}\left(u_{R}\left(a_{1}\right)+w+v_{2}\right) d F\left(v_{2}\right)+\int_{-w}^{-w-u_{R}\left(a_{1}\right)}\left(w+v_{2}\right) d F\left(v_{2}\right)\right]\right) \\
& =u_{R}\left(a_{1}\right)-\delta p\left(r(0,1)\left[\int_{w}^{w+u_{L}\left(a_{1}\right)}\left(u_{R}\left(a_{1}\right)+w+v_{2}\right) d F\left(v_{2}\right)\right]\right. \\
& \left.\quad+(1-r(0,1))\left[\int_{w}^{w+u_{L}\left(a_{1}\right)}\left(u_{R}\left(a_{1}\right)+w+v_{2}\right) d F\left(v_{2}\right)+\int_{-w-u_{R}\left(a_{1}\right)}^{w} u_{R}\left(a_{1}\right) d F\left(v_{2}\right)\right]\right) .
\end{aligned}
$$

Since $u_{R}\left(a_{1}\right)<0$, the upper bound for party $R^{\prime}$ s net gain of passing $a_{1}(29)$ occurs when $r(0,1)=0$, i.e., the voter elects party $L$ when party $R$ is pivotal and vetoes $a_{1}$. This upper 
bound is equal to

$$
\begin{aligned}
& u_{R}\left(a_{1}\right)-\delta p\left[\int_{w}^{w+u_{L}\left(a_{1}\right)}\left(u_{R}\left(a_{1}\right)+w+v_{2}\right) d F\left(v_{2}\right)+\int_{-w-u_{R}\left(a_{1}\right)}^{w} u_{R}\left(a_{1}\right) d F\left(v_{2}\right)\right] \\
& =u_{R}\left(a_{1}\right)\left(1-\delta p \int_{-w-u_{R}\left(a_{1}\right)}^{w+u_{L}\left(a_{1}\right)} d F\left(v_{2}\right)\right)-\delta p\left[\int_{w}^{w+u_{L}\left(a_{1}\right)}\left(w+v_{2}\right) d F\left(v_{2}\right)\right]
\end{aligned}
$$

which is negative since $u_{R}\left(a_{1}\right)<0$. That is, for any strategy of the voter, $r$, party $R$ strictly prefers that $a_{1}$ not pass when they are pivotal and, hence, $a_{1}$ will not pass. We conclude that preference-based gridlock occurs with the same probability when the voter does and does not have commitment power.

Proof of Proposition 12. We begin by establishing the expected payoff to the voter when policy bundling is and isn't possible, which we denote by $E U_{b=1}$ and $E U_{b=0}$, respectively. When policy bundling is not possible, the voter's expected payoff is simply

$$
\frac{1}{2} E U_{b=0}=\int_{-\infty}^{-w} \delta \int_{-w}^{w} w d F\left(v_{2}\right) d F\left(v_{1}\right)+\int_{-w}^{w}\left(w+\delta \int_{-w}^{w} w d F\left(v_{2}\right)\right) d F\left(v_{1}\right) .
$$

When policy bundling is possible, the voter's expect payoff is

$$
\begin{aligned}
& \frac{1}{2} E U_{b=1} \\
& =\int_{-\infty}^{-3 w}\left((1-p) \delta \int_{-w}^{w} w d F\left(v_{2}\right)+p \delta\left(\int_{-w}^{w} w d F\left(v_{2}\right)+\int_{-w-u_{R}\left(a_{1}\right)}^{w+u_{L}\left(a_{1}\right)} 2 w d F\left(v_{2}\right)\right)\right) d F\left(v_{1}\right) \\
& +\int_{-3 w}^{-w}\left((1-p) \delta \int_{-w}^{w} w d F\left(v_{2}\right)+p \delta\left(\int_{-w}^{-w-u_{R}\left(a_{1}\right)} w d F\left(v_{2}\right)\right.\right. \\
& \left.\left.\quad+\int_{-w-u_{R}\left(a_{1}\right)}^{w+u_{L}\left(a_{1}\right)} 2 w d F\left(v_{2}\right)\right)\right) d F\left(v_{1}\right) \\
& +\int_{v_{1} \in(-w, 0): \Phi_{R}\left(v_{1}\right)>0}\left[w+\delta \int_{-w}^{w} w d F\left(v_{2}\right)\right] d F\left(v_{1}\right) \\
& +\int_{v_{1} \in(-w, 0): \Phi_{R}\left(v_{1}\right)<0}\left[(1-p) \delta \int_{-w}^{w} w d F\left(v_{2}\right)+\delta p w+\delta p \int_{-w}^{w+u_{L}\left(a_{1}\right)} w d F\left(v_{2}\right)\right] d F\left(v_{1}\right) .
\end{aligned}
$$


The net gain from policy bundling, denoted by $N E U_{b=1}$, is

$$
\begin{aligned}
\frac{1}{2} N E U_{b=1}= & \int_{-\infty}^{-3 w} p \delta\left(\int_{-w-u_{R}\left(a_{1}\right)}^{w+u_{L}\left(a_{1}\right)} 2 w d F\left(v_{2}\right)\right) d F\left(v_{1}\right) \\
& +\int_{-3 w}^{-w} p \delta\left(-\int_{-w}^{w} w d F\left(v_{2}\right)+\int_{-w}^{-w-u_{R}\left(a_{1}\right)} w d F\left(v_{2}\right)\right. \\
& \left.\quad+\int_{-w-u_{R}\left(a_{1}\right)}^{w+u_{L}\left(a_{1}\right)} 2 w d F\left(v_{2}\right)\right) d F\left(v_{1}\right) \\
& +\int_{v_{1} \in(-w, 0): \Phi_{R}\left(v_{1}\right)<0}\left[-w-p \delta \int_{-w}^{w} w d F\left(v_{2}\right)+\delta p w\right. \\
= & \left.\quad+\delta p \int_{-\infty}^{w+u_{L}\left(a_{1}\right)} w d F\left(v_{2}\right)\right] d F\left(v_{1}\right) \\
& +\int_{-3 w}^{-3 w} p \delta\left(\int_{-w-u_{R}\left(a_{1}\right)}^{w+u_{L}\left(a_{1}\right)} w d F\left(v_{2}\right)+\int_{-w-u_{R}\left(a_{1}\right)}^{w+u_{L}\left(a_{1}\right)} w d F\left(v_{2}\right)\right) d F\left(v_{1}\right) \\
& -\int_{v_{1} \in(-w, 0): \Phi_{R}\left(v_{1}\right)<0}^{w+u_{L}\left(a_{1}\right)}\left[w(1-\delta p)-\delta p \int_{w}^{w+u_{L}\left(a_{1}\right)} w d F\left(v_{2}\right)\right] d F\left(v_{1}\right) .
\end{aligned}
$$

This can be further simplified to

$$
\begin{aligned}
\frac{1}{2} N E U_{b=1}= & 2 w p \delta \int_{-\infty}^{-3 w}\left[F\left(2 w-v_{1}\right)-F\left(-2 w-v_{1}\right)\right] d F\left(v_{1}\right) \\
& +p \delta w \int_{-3 w}^{-w}\left[F\left(2 w-v_{1}\right)-F(w)+F\left(2 w-v_{1}\right)-F\left(-2 w-v_{1}\right)\right] d F\left(v_{1}\right) \\
& -w \int_{v_{1} \in(-w, 0): \Phi_{R}\left(v_{1}\right)<0}\left((1-\delta p)-\delta p\left[F\left(2 w-v_{1}\right)-F(w)\right]\right) d F\left(v_{1}\right)
\end{aligned}
$$

Note that the first two integrands of (31) are positive and, hence, $N E U_{b=1}$ will be positive if the third integrand is negative or positive but sufficiently small. As a result, we attain two sufficient conditions for $N E U_{b=1}>0$. First, if $F(w)-F(-w)$ is sufficiently small. Second, if for all $v \in(-w, 0)$

$$
(1-\delta p)-\delta p\left[F\left(2 w-v_{1}\right)-F(w)\right]<0,
$$


i.e,

$$
[F(2 w)-F(w)]>1 /(\delta p)-1
$$

which corresponds precisely to the condition in Proposition 9 for leverage-based gridlock to always be efficient.

Proof of Proposition 13. We wish to show that, for certain parameters, policy bundling reduces the voter's expected payoff, i.e., (31) is negative. To prove this claim we will consider a family of distributions, indexed by a parameter $\varepsilon>0$, and then via a limit argument prove that for sufficiently small $\varepsilon>0(31)$ is negative.

We define this family of distributions formally and then provide some intuition after. Given $\varepsilon>0$, let $F_{\varepsilon}$ be a symmetric distribution, i.e., $F_{\varepsilon}(-v)=1-F_{\varepsilon}(v) \forall v$ such that

$$
\begin{aligned}
F_{\varepsilon}(-w) & =\varepsilon \quad \text { and }, \\
F_{\varepsilon}\left(-w+\frac{\delta p}{1-\delta p} \varepsilon w\right)-F_{\varepsilon}(-w) & =\frac{1}{2}-\varepsilon .
\end{aligned}
$$

The distribution $F_{\varepsilon}$ distributes its mass evenly about zero, a small portion of mass $2 \varepsilon>$ 0 is distributed outside of $[-w, w]$, and the remaining mass is distributed close to the boundaries of $[-w, w]$.

The key idea is that policy bundling reduces voter welfare (relative to the no policy bundling case) when inefficient leverage-based gridlock occurs frequently. Thus, we wish to show the existence of a distribution such that inefficient leverage-based gridlock occurs frequently enough so that its cost to voter welfare dominates any voter welfare gains that follow from policy bundling and the possibility of period-2 compromises. However, there are two competing forces that complicate this trade-off. (Inefficient) leverage-based gridlock only occurs when the period-1 alternative is bipartisan, but the more likely it is that alternatives are bipartisan the less incentive there is for each party to engage in leverage-based gridlock.

The distributions $F_{\varepsilon}$ that we construct are designed so that as the probability of bipar- 
tisan alternatives increases, the party with lowest-payoff has a payoff that decreases fast enough such that there is an overall increase in the frequency of leverage-based gridlock. We now proceed with the proof. As per (31), the net benefit of policy bundling is

$$
\begin{aligned}
\frac{1}{2} N E U_{b=1}= & 2 w p \delta \int_{-\infty}^{-3 w}\left[F_{\varepsilon}\left(2 w-v_{1}\right)-F_{\varepsilon}\left(-2 w-v_{1}\right)\right] d F_{\varepsilon}\left(v_{1}\right) \\
& +p \delta w \int_{-3 w}^{-w}\left[F_{\varepsilon}\left(2 w-v_{1}\right)-F_{\varepsilon}(w)+F_{\varepsilon}\left(2 w-v_{1}\right)-F_{\varepsilon}\left(-2 w-v_{1}\right)\right] d F_{\varepsilon}\left(v_{1}\right) \\
& -w \int_{v_{1} \in(-w, 0): \Phi_{R}\left(v_{1}\right)<0}\left((1-\delta p)-\delta p\left[F_{\varepsilon}\left(2 w-v_{1}\right)-F_{\varepsilon}(w)\right]\right) d F_{\varepsilon}\left(v_{1}\right),
\end{aligned}
$$

where

$$
\Phi_{R}\left(v_{1}\right)=u_{R}\left(a_{1}\right)(1-\delta p)-\delta p \int_{w}^{w+u_{L}\left(a_{1}\right)}\left(w+v_{2}\right) d F_{\varepsilon}\left(v_{2}\right)
$$

Given the distribution $F_{\varepsilon}, \Phi_{R}\left(v_{1}\right)<0$ for all $v_{1} \in(-w, 0)$ that have a positive density. To see this, notice that

$$
\begin{aligned}
\Phi_{R}\left(v_{1}\right) & <\left(w+v_{1}\right)(1-\delta p)-\delta p w\left[F_{\varepsilon}(2 w)-F_{\varepsilon}(w)\right] \\
& =\left(w+v_{1}\right)(1-\delta p)-\delta p w \varepsilon .
\end{aligned}
$$

Furthermore, since for all bipartisan alternatives we have that $-w<v_{1}<-w+\frac{\delta p}{1-\delta p} \varepsilon w$ with probability one, we can infer that

$$
\Phi_{R}\left(v_{1}\right)<\frac{\delta p}{1-\delta p} \varepsilon w(1-\delta p)-\delta p w \varepsilon=0
$$

Thus, (32) simplifies to

$$
\begin{aligned}
\frac{1}{2} N E U_{b=1}= & 2 w p \delta \int_{-\infty}^{-3 w}\left[F_{\varepsilon}\left(2 w-v_{1}\right)-F_{\varepsilon}\left(-2 w-v_{1}\right)\right] d F_{\varepsilon}\left(v_{1}\right) \\
& +p \delta w \int_{-3 w}^{-w}\left[F_{\varepsilon}\left(2 w-v_{1}\right)-F_{\varepsilon}(w)+F_{\varepsilon}\left(2 w-v_{1}\right)-F_{\varepsilon}\left(-2 w-v_{1}\right)\right] d F_{\varepsilon}\left(v_{1}\right) \\
& -w \int_{v_{1} \in(-w, 0)}\left((1-\delta p)-\delta p\left[F_{\varepsilon}\left(2 w-v_{1}\right)-F_{\varepsilon}(w)\right]\right) d F_{\varepsilon}\left(v_{1}\right)
\end{aligned}
$$


Utilizing the definition of $F_{\varepsilon}$, we now provide an upper bound for $N E U_{b=1}$.

$$
\begin{aligned}
\frac{1}{2} N E U_{b=1}< & 2 w p \delta \int_{-\infty}^{-3 w} \varepsilon d F_{\varepsilon}\left(v_{1}\right)+p \delta w \int_{-3 w}^{-w}[\varepsilon+1] d F_{\varepsilon}\left(v_{1}\right) \\
& -w \int_{-w}^{-w+\frac{\delta p}{1-\delta_{p}} \varepsilon w}\left((1-\delta p)-\delta p\left[F_{\varepsilon}\left(2 w-v_{1}\right)-F_{\varepsilon}(w)\right]\right) d F_{\varepsilon}\left(v_{1}\right) \\
< & 2 w p \delta \varepsilon^{2}+p \delta w \varepsilon[\varepsilon+1]-w \int_{-w}^{-w+\frac{\delta p}{1-\delta_{p}} \varepsilon w}((1-\delta p)-\delta p \varepsilon) d F_{\varepsilon}\left(v_{1}\right) \\
< & 2 w p \delta \varepsilon^{2}+p \delta w \varepsilon[\varepsilon+1]-w\left(\frac{1}{2}-\varepsilon\right)((1-\delta p)-\delta p \varepsilon) .
\end{aligned}
$$

As $\varepsilon \rightarrow 0$, the righthand side of the (34) approaches $-w \frac{1}{2}(1-\delta p)$, which is negative. We conclude that there exists a family of distributions such that voter welfare is higher when parties cannot engage in policy bundling. 